\title{
Recent advances in upper gastrointestinal lymphomas: molecular updates and diagnostic implications
}

\author{
Periklis G Foukas, ${ }^{1}$ (D) Bettina Bisig ${ }^{2}$ (D) \& Laurence de Leval $^{1}$ (D) \\ ${ }^{1}$ Second Department of Pathology, National and Kapodistrian University of Athens, Attikon University Hospital, \\ Athens, Greece, and ${ }^{2}$ Department of Laboratory Medicine and Pathology, Institute of Pathology, Lausanne University \\ Hospital and Lausanne University, Lausanne, Switzerland
}

Foukas P G, Bisig B \& de Leval L.

(2021) Histopathology 78, 187-214. https://doi.org/10.1111/his.14289

\section{Recent advances in upper gastrointestinal lymphomas: molecular updates and diagnostic implications}

Approximately one-third of extranodal non-Hodgkin lymphomas involve the gastrointestinal (GI) tract, with the vast majority being diagnosed in the stomach, duodenum, or proximal small intestine. A few entities, especially diffuse large B-cell lymphoma and extranodal marginal zone lymphoma of mucosa-associated lymphoid tissue, represent the majority of cases. In addition, there are diseases specific to or characteristic of the GI tract, and any type of systemic lymphoma can present in or disseminate to these organs. The recent advances in the genetic and molecular characterisation of lymphoid neoplasms have translated into notable changes in the classification of primary GI T-cell neoplasms and the recommended diagnostic approach to aggressive B-cell tumours. In many instances, diagnoses rely on morphology and immunophenotype, but there is an increasing need to incorporate molecular genetic markers. Moreover, it is also important to take into consideration the endoscopic and clinical presentations. This review gives an update on the most recent developments in the pathology and molecular pathology of upper GI lymphoproliferative diseases.

Keywords: differential diagnosis, duodenum, enteropathy-associated T-cell lymphoma, fluorescent in situ hybridization, gastrointestinal lymphomas, indolent lymphoproliferative disorders, MALT lymphoma, molecular pathology, small intestine, stomach

\section{Introduction}

Lymphomas involving the gastrointestinal (GI) tract account for approximately $30-40 \%$ of extranodal lymphomas. ${ }^{1,2}$ The notion of primary GI lymphomas, in principle, refers to tumours arising in the GI tract with the bulk of the tumour localised to a specific GI organ, with or without regional involvement. By extension, the term also encompasses situations in which the clinical presentation is related to

\footnotetext{
Address for correspondence: L de Leval, MD, PhD, Institute of Pathology, Centre Hospitalier Universitaire Vaudois, Rue du Bugnon 25, CH-1011, Lausanne, Switzerland. e-mail: laurence. deleval@chuv.ch
}

lymphoma involvement of a GI site, and staging reveals disseminated disease. In addition, the GI tract can be affected by contiguous involvement or dissemination of a systemic disease. Primary oesophageal lymphomas are extremely rare, accounting for $<1 \%$ of GI lymphomas, ${ }^{2-4}$ with most cases probably representing extension from posterior mediastinal masses or gastric primaries. The stomach alone accounts for the majority of GI lymphomas $(60 \%$ of the cases), $\sim 30 \%$ arise in the duodenum or small intestine and ileocaecal region, and $\sim 10 \%$ affect the colon. $^{1-6}$

Most GI lymphoma cases correspond to entities that are not specific to the GI tract, with specific tumour entities primarily arising in the GI tract representing 
a smaller proportion, including duodenal-type follicular lymphoma (FL) and intestinal T-cell lymphomas. The prevalence of the different lymphoma entities varies according to the site of involvement, i.e. stomach versus duodenum and small intestine versus colon (Table 1).

In this article, we present an update on the pathological and molecular features of the lymphoid neoplasms that most commonly involve the upper GI tract, with an emphasis on the new guidelines derived from the latest updates of the World Health Organization (WHO) classification of tumours of haematopoietic and lymphoid tissues ${ }^{7}$ and the digestive system, ${ }^{8}$ and a focus on more recent developments.

\section{Small B-cell lymphomas}

Although essentially any small B-cell lymphoma may infiltrate the upper GI tract, primary GI presentation is dominated by extranodal marginal zone lymphoma of mucosa-associated lymphoid tissue (MALT lymphoma) in the stomach and the small intestine in general, and duodenal-type FL in that specific site. A diagnostic approach to lympho(plasma)cytic infiltrates in the upper GI mucosa is shown in Figure 1, and Table 2 summarises the antibodies commonly used to assist in the differential diagnosis in routine practice.

Table 1. Relative prevalence of lymphomas in different parts of the gastrointestinal tract

\begin{tabular}{|c|c|c|c|}
\hline Lymphomas & $\begin{array}{l}\text { Stomach } \\
(\%)\end{array}$ & $\begin{array}{l}\text { Small intestine } \\
(\%)\end{array}$ & $\begin{array}{l}\text { Colon } \\
(\%)\end{array}$ \\
\hline $\begin{array}{l}\text { Gastrointestinal } \\
\text { lymphomas }\end{array}$ & 60 & $25-30$ & $5-10$ \\
\hline Primary neoplasms & $<5$ & $30-50$ & $<1$ \\
\hline $\begin{array}{l}\text { Diffuse large B-cell } \\
\text { lymphomas }\end{array}$ & $40-50$ & $40-60$ & $>40$ \\
\hline MALT lymphoma & $40-50$ & $5-15$ & 25 \\
\hline Follicular lymphoma & Rare & $1-10$ & Rare \\
\hline Mantle cell lymphoma & $<5$ & $<5$ & 25 \\
\hline Burkitt lymphoma & $<1$ & $<5$ & $<1$ \\
\hline $\begin{array}{l}\text { Intestinal T-cell } \\
\text { lymphomas }\end{array}$ & Rare & 15 & Rare \\
\hline $\begin{array}{l}\text { Post-transplant and ID- } \\
\text { related }\end{array}$ & Rare & Rare & Rare \\
\hline
\end{tabular}

ID, Immunodeficiency; MALT, Mucosa-associated lymphoid tissue.

\section{MALT LYMPHOMA}

MALT lymphoma, an indolent B-cell lymphoma recapitulating the morphology and architectural features of mucosa-associated lymphoid tissue (MALT), accounts for $40-50 \%$ of primary gastric lymphomas and a much smaller proportion $(5-15 \%)$ of lymphomas arising in the small intestine. ${ }^{1-3,9,10}$ Patients are usually adults and present with non-specific symptoms such as dyspepsia, nausea, epigastric pain, or bleeding, or may be asymptomatic. Immunoproliferative small intestinal disease (IPSID) is a rare variant of intestinal MALT lymphoma associated with the secretion of defective $\alpha$ heavy chains, and is largely restricted to the eastern Mediterranean area, the Middle and Far East, and Africa. This disease, which usually develops in the duodenum and jejunum, affects young adults of lower socioeconomic status and living in poor hygienic conditions, who present with malabsorption, diarrhoea, abdominal pain, and weight loss. ${ }^{11,12}$

\section{Association with infectious agents}

MALT lymphomas usually occur in tissues naturally devoid of MALT, and develop in a context of chronic inflammation induced by infections or autoimmune disorders. ${ }^{13,14}$ Epidemiological, biological and therapeutic studies have shown a strong link between Helicobacter pylori infection and gastric MALT lymphoma. ${ }^{15,16}$ Following an initial study by Wotherspoon et al., several groups have confirmed that eradication of $H$. pylori following antibiotic therapy induces regression of MALT lymphoma in $\sim 75 \%$ of early-stage tumours. ${ }^{17-20}$ In earlier reports, H. pylori infection was demonstrated in $>90 \%$ of cases. $^{21-23}$ However, recent analyses have shown a significant reduction in the prevalence of $H$. pylori infection in gastric MALT lymphomas in Europe as compared with the early 1990s. ${ }^{24}$ In a retrospective study of $>400$ cases diagnosed in France between 2002 and 2010 , only $57 \%$ of the cases were associated with $H$. pylori. ${ }^{25}$ Another point is that the density and detectability of $H$. pylori have been reported to decrease in association with lymphoma progression. ${ }^{26,27}$ In intestinal MALT lymphomas, an association with Campylobacter jejuni infection has been reported, but evidence for a causal link is lacking. ${ }^{28}$

\section{Pathological features}

Endoscopically, MALT lymphoma may present as subtle gastritis-like lesions, erosions, and ulcerations, or as diffuse infiltrates and thickened folds, which may form polypoid or exophytic mass lesions. Endoscopic 


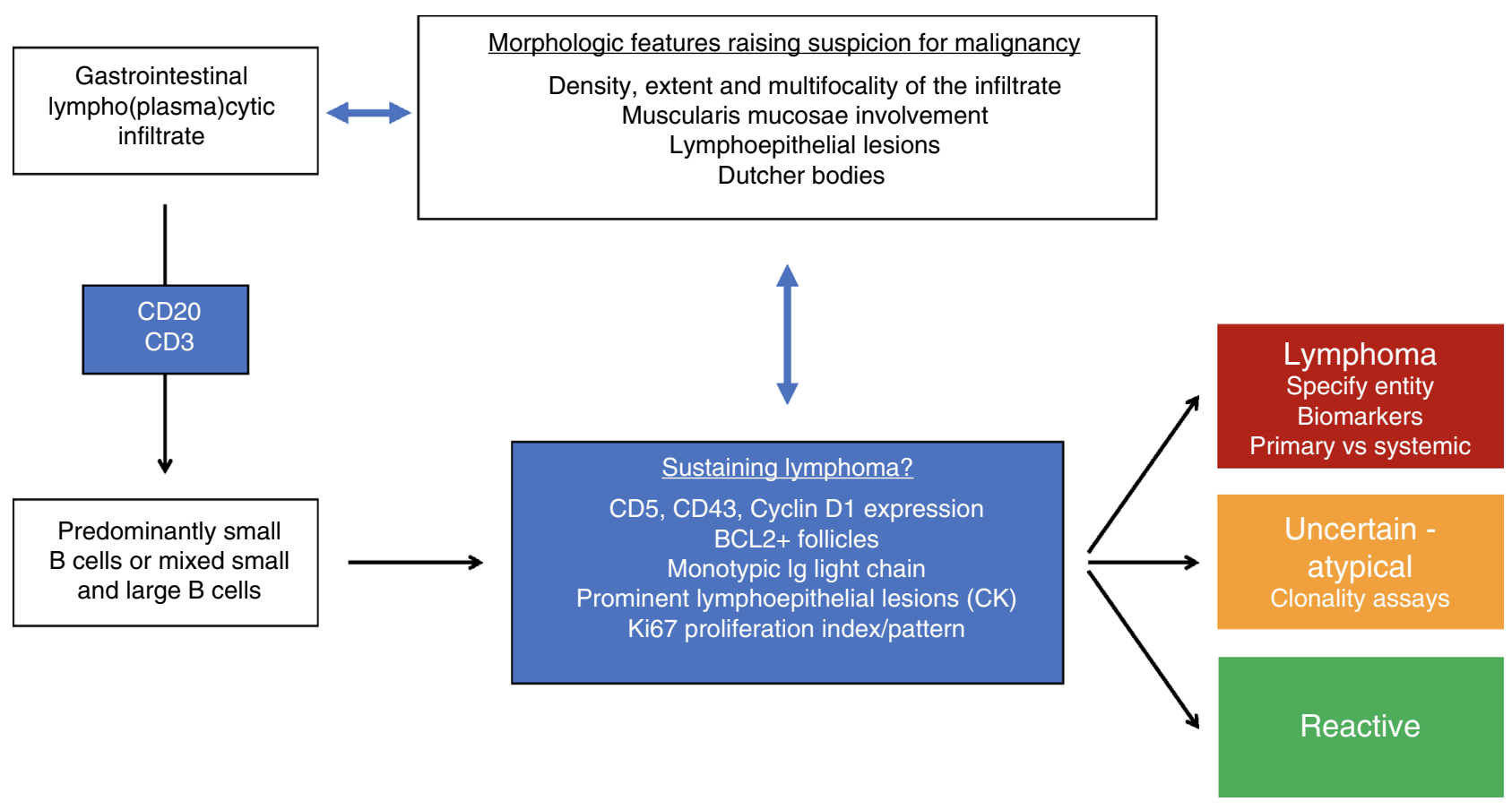

Figure 1. Diagnostic approach to lympho(plasma)cytic infiltrates in the gastrointestinal mucosa. CK, cytokeratin.

ultrasonography is the most accurate staging method for assessment of the depth of invasion and the status of regional lymph nodes. ${ }^{29,30}$ The Lugano and Paris staging systems are most commonly used, with the second describing more accurately the depth of gastric wall invasion, a parameter that may predict the response to anti-H. pylori treatment. ${ }^{30}$

Histologically, the cardinal features of MALT lymphoma are: (i) a diffuse and/or nodular infiltrate of neoplastic lymphoid B cells cytologically resembling marginal zone B cells; (ii) lymphoepithelial lesions; and (iii) reactive lymphoid follicles with germinal centres. $^{31,32}$ The neoplastic population comprises small to medium-sized lymphoid cells, with a centrocyte-like or monocytoid appearance, which infiltrate diffusely into the mucosa and frequently colonise reactive germinal centres (Figure 2). There can be cytological variation: some tumours contain a relatively monotonous population, whereas others feature a mixture of cell types. The neoplastic infiltrate also usually contains scattered, large, transformed blastic cells resembling centroblasts or immunoblasts. Plasma cell differentiation is seen in $\sim 30 \%$ of cases (Figure 3). The neoplastic plasma cells may appear as normal mature plasma cells, have crystalline inclusions in the cytoplasm, or possess nuclei with Dutcher bodies. Lymphoepithelial lesions, defined as the invasion of individual gastric pits and/or glands by aggregates (three or more) of neoplastic cells, often resulting in oxyphilic changes in the epithelium, constitute a characteristic feature of gastric MALT lymphoma, but are found infrequently in MALT lymphomas of the small intestine. The destruction and disintegration of the epithelial structures induce degenerative epithelial changes manifested by eosinophilic or oncocytic metaplasia. Notably, although lymphoepithelial lesions in the stomach are highly suggestive of MALT lymphoma, occasional lymphoepithelial lesions may be seen in florid gastritis, so they are not specific for a diagnosis of malignancy. Moreover, other lymphomas may show epitheliotropism and produce alterations resembling lymphoepithelial lesions. In particular, epitheliotropism is a defining property of monomorphic epitheliotropic intestinal T-cell lymphoma, which, by morphology alone, may mimic MALT lymphoma in the stomach. Epitheliotropism is commonly seen in extranodal natural killer (NK)/Tcell lymphoma, which rarely involves the stomach, and is occasionally encountered in other B-cell lymphoma types such as diffuse large B-cell lymphoma (DLBCL) or, less commonly, mantle cell lymphoma (MCL).

The lymphoma cells are positive for pan-B-cell antigens (CD19, CD20, CD79a, and PAX5), and usually 
Table 2. Antibodies used in the (differential) diagnosis of gastrointestinal B-cell lympho(plasma)cytic infiltrates

\begin{tabular}{|c|c|c|}
\hline Antigens & Normal cells & Diagnostic utility \\
\hline $\begin{array}{l}\text { CD20 } \\
\text { PAX5 } \\
\text { CD79a }\end{array}$ & B-cell lineage antigens & $\begin{array}{l}\text { Usually strong and diffuse expression in B-cell lymphomas. Weak } \\
\text { CD20 staining in CLL/SLL. Reduced or absent CD20 expression in } \\
\text { patients with previous immunochemotherapy comprising anti-CD20 } \\
\text { antibodies. Weak or negative in plasmablastic lymphoma }\end{array}$ \\
\hline $\begin{array}{l}\text { CD3 } \\
\text { CD5 }\end{array}$ & $\begin{array}{l}\text { T-cell antigen } \\
\text { Weakly expressed in mantle cells of follicles }\end{array}$ & $\begin{array}{l}\text { CD5 expression in CLL/SLL and MCL, rarely in MALT lymphoma, and } \\
\text { in a subset of DLBCLs NOS }\end{array}$ \\
\hline CD10 & Germinal centre B cells & $\begin{array}{l}\mathrm{CD} 10 \text { expression in } \mathrm{FL}, \mathrm{BL} \text {, and a subset of DLBCLs NOS (germinal } \\
\text { centre-B-cell like). Rarely positive in blastoid MCL. Positive in } \\
\text { reactive follicles in MALT lymphoma }\end{array}$ \\
\hline CD21 & Mature B cells and FDCs & $\begin{array}{l}\text { Helpful to identify reactive or neoplastic follicular structures in MALT } \\
\text { lymphoma and FL }\end{array}$ \\
\hline CD23 & Activated B cells, mantle B cells of follicles, FDCs & $\begin{array}{l}\text { CD23 expression CLL/SLL, and a subset of FLs and DLBCLs. Lack of } \\
\text { CD23 expression in MCL. Helpful to identify reactive or neoplastic } \\
\text { follicular structures in MALT lymphoma and FL }\end{array}$ \\
\hline CD43 & Pan-T-cell antigen, monocytes, activated B cells & $\begin{array}{l}\text { CD43 expression in MCL and CLL/SLL (most cases, but sometimes } \\
\text { not detectable on routine sections), positive in a subset of MALT } \\
\text { lymphomas }\end{array}$ \\
\hline $\mathrm{bcl}-2$ & $\begin{array}{l}\text { Antiapoptotic molecule down-regulated in germinal } \\
\text { centre B cells }\end{array}$ & $\begin{array}{l}\text { bcl-2+ neoplastic follicles in } \mathrm{FL} \\
\text { bcl-2-reactive follicles in MALT lymphomas } \\
\text { Lack of bcl-2 expression typical of } \mathrm{BL} \\
\text { Expression in }>50 \% \text { of neoplastic cells defines bcl-2+ (bcl-2+) DLBCL; } \\
\text { usually very strong and diffuse positivity in } B C L 2 \text {-rearranged } \\
\text { lymphomas }\end{array}$ \\
\hline bcl-6 & $\begin{array}{l}\text { Transcription factor of germinal centre B cells and } \\
\text { follicular helper T cells }\end{array}$ & $\begin{array}{l}\text { bcl-6 expression in } \mathrm{FL}, \mathrm{BL} \text {, a subset of DLBCLs NOS, and high-grade } \\
\text { B-cell lymphomas }\end{array}$ \\
\hline Cyclin D1 & $\begin{array}{l}\text { No expression by normal B cells. Positive } \\
\text { endothelial cells and macrophages are internal } \\
\text { controls }\end{array}$ & $\begin{array}{l}\text { Very sensitive and highly specific marker for MCL. Also expressed in } \\
\text { some DLBCLs and in proliferation centres of CLL/SLL }\end{array}$ \\
\hline LEF1 & Activated T cells & Expressed in CLL/SLL cells \\
\hline SOX11 & No known expression in normal lymphoid tissues & $\begin{array}{l}\text { Expressed in a subset of } M C L s \text {, useful to identify the rare cyclin D1- } \\
\text { negative } M C L\end{array}$ \\
\hline Ki67 & Nuclei of cycling cells & $\begin{array}{l}\text { Ki67 proliferative index reflective of high-grade and low-grade } \\
\text { entities. Usually low in small B-cell lymphomas, with residual Ki67- } \\
\text { high germinal centres in MALT lymphomas; prognostic factor in } \\
\text { MCL. Ki67 index close to } 100 \% \text { in BL and variably high in other } \\
\text { aggressive B-cell neoplasms }\end{array}$ \\
\hline $\begin{array}{l}\kappa \text { and } \lambda \\
\text { light } \\
\text { chains }\end{array}$ & $\begin{array}{l}\text { B cells (membrane Ig expression) and plasma cells } \\
\text { (cytoplasmic Ig expression). Normal } \kappa \text { to } \lambda \text { ratio: } \\
2: 1\end{array}$ & $\begin{array}{l}\text { Restricted (monotypic) light chain expression in neoplastic cells versus } \\
\text { polytypic expression in reactive lymphoproliferations }\end{array}$ \\
\hline Cytokeratins & Surface epithelium, crypts and glands & Demonstration of lymphoepithelial lesions \\
\hline
\end{tabular}

bcl-2, B-cell lymphoma 2; bcl-6, B-cell lymphoma 6; BL, Burkitt lymphoma; CLL, Chronic lymphoid leukaemia; DLBCL, Diffuse large B-cell lymphoma; FDC, Follicular dendritic cell; FL, Follicular lymphoma; Ig, Immunoglobulin; LEF1, Lymphoid enhancer factor 1; MALT, Mucosaassociated lymphoid tissue; MCL, Mantle cell lymphoma; NOS, Not otherwise specified; SLL, Small lymphocytic lymphoma; SOX11, SRYbox transcription factor 11 .

negative for $\mathrm{CD} 5$, with aberrant coexpression of CD43 in approximately one-third of the cases. ${ }^{33}$ The rare cases of CD5+ MALT lymphoma must be distinguished from small lymphocytic lymphoma (SLL) and MCL. MALT lymphoma cells are negative for the germinal centre markers CD10 and B-cell 

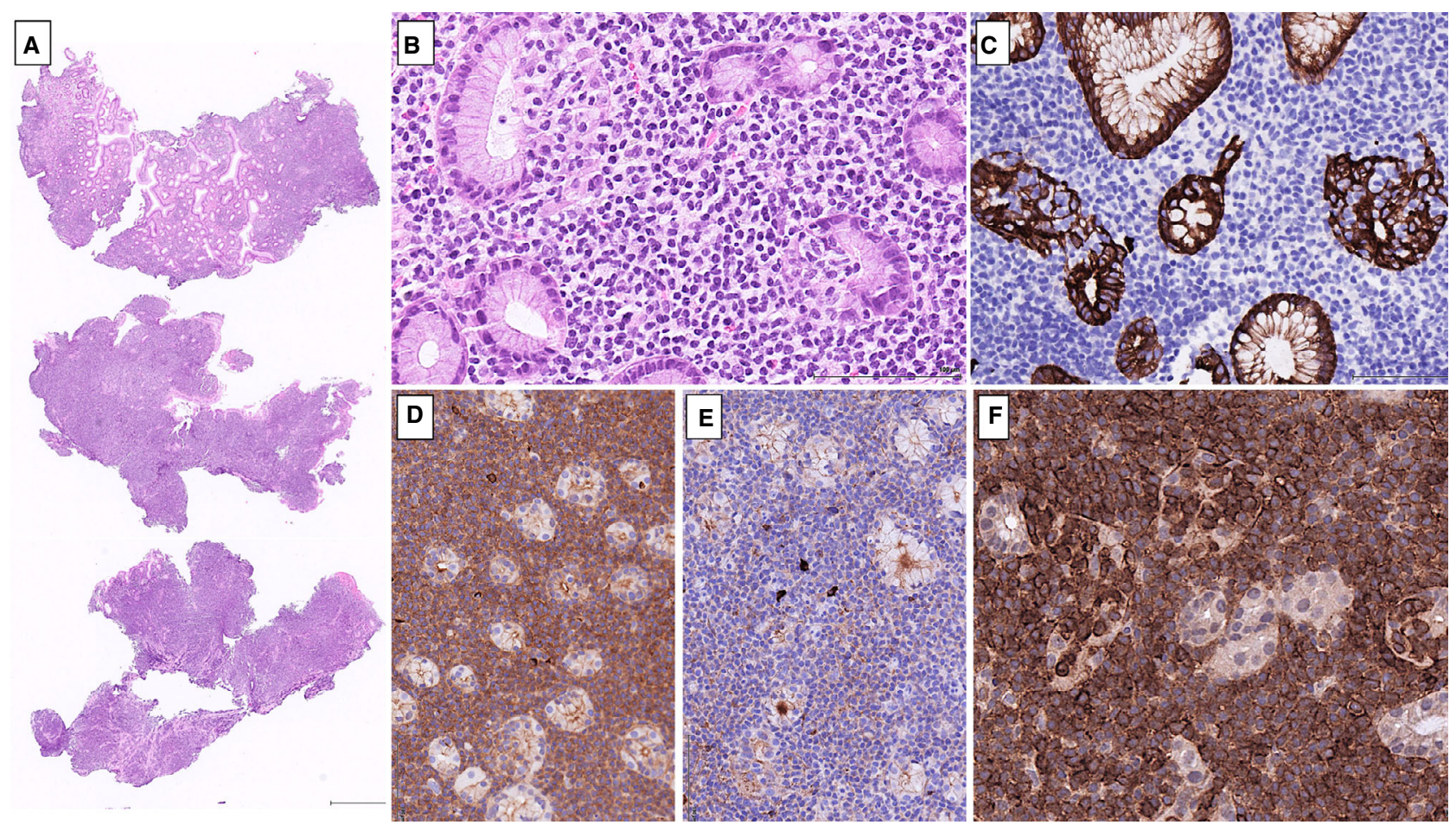

Figure 2. Gastric mucosa-associated lymphoid tissue lymphoma. A, Panoramic view showing a diffuse lymphoid infiltrate, disrupting the glands and the muscularis mucosae [haematoxylin and eosin (H\&E)]. B, A diffuse infiltrate of small centrocyte-like cells with moderate amounts of clear cytoplasm, forming lymphoepithelial lesions (H\&E). C, Cytokeratin immunostain highlighting the lymphoepithelial lesions. D, Positivity for lambda light chains. E, Negativity for kappa light chains. F, Immune receptor translocation-associated protein 1 (IRTA 1) positivity of lymphoma cells, especially pronounced among the subset of intraepithelial lymphocytes.

lymphoma 6 (bcl-6), negative for the MCL markers cyclin D1 and SRY-box transcription factor 11 (SOX11), and usually express B-cell lymphoma 2 (bcl-2). They are negative for IgD and express monotypic IgG, IgM or IgA with either kappa or lambda light chain, a feature best demonstrated in cases with plasmacytoid differentiation. Antibodies against keratins highlight lymphoepithelial lesions, and follicular dendritic cell markers, such as CD21, CD23, and CD35, are useful for highlighting follicular structures and identifying follicular colonisation. The Ki67 proliferation index is low outside of residual germinal centres. Immune receptor translocation-associated protein 1 (IRTA1) was recently characterised as a potentially useful biomarker with which to identify MALT lymphomas and distinguish them from other small B-cell lymphomas. IRTA1 belongs to a family of immunoglobulin-like proteins that mediate B-cell immune responses, and is normally expressed in benign monocytoid B cells, some marginal zone cells, and intraepithelial B cells. ${ }^{34}$ IRTA1 expression has been reported in $40 \%$ to $>90 \%$ of MALT lymphomas, whereas other small B-cell lymphomas are, with few exceptions, IRTA1-negative. ${ }^{35,36}$

\section{Molecular genetics/pathogenesis}

Adding to the growth signals provided by infiltrating H. pylori-specific T cells, ${ }^{37,38}$ activation of the B-cell receptor (BCR) and nuclear factor- $\kappa \mathrm{B}(\mathrm{NF}-\kappa \mathrm{B})$ signalling pathways plays a major role in gastric MALT lymphoma development. Sequence analysis of immunoglobulin (IG) gene rearrangements shows evidence of somatic hypermutations, with an active ongoing somatic hypermutation machinery resulting in intraclonal variation and a biased usage of certain immunoglobulin heavy chain (IGH) genes, such as IGHV3-7 and IGHV1-69, indicating a selective pressure towards antigen-driven clonal expansion. ${ }^{39-43}$

Several recurrent chromosomal translocations are associated with MALT lymphomas. They are mutually exclusive, and their relative frequencies vary with the primary site of involvement. The most frequent in the GI tract is the $\mathrm{t}(11 ; 18)(\mathrm{q} 21 ; \mathrm{q} 21) /$ BIRC3-MALT1 translocation, found in approximately $25 \%$ of gastric 

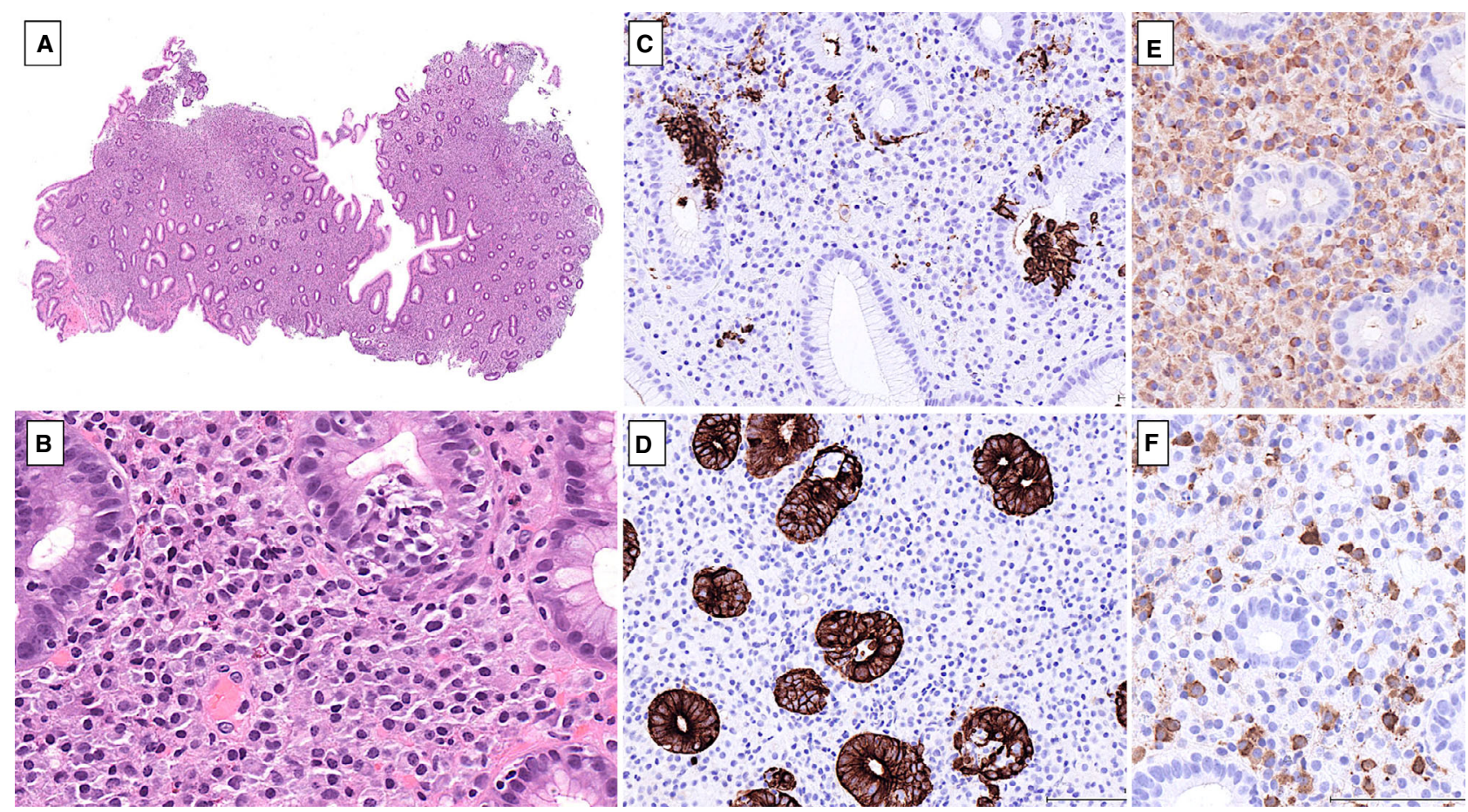

Figure 3. Gastric mucosa-associated lymphoid tissue lymphoma with marked plasmacytic differentiation. A, A panoramic view showing a diffuse mucosal infiltrate with atrophy and rarefaction of the glands [haematoxylin and eosin (H\&E)]. B, Lymphoepithelial lesions and a diffuse plasmacytic infiltrate in the lamina propria (H\&E). C, CD20 highlighting the aggregates of intraepithelial lymphocytes, and only a few cells between the glands. D, Cytokeratin immunostain highlighting the lymphoepithelial lesions. E, Staining for lambda light chains of the majority of plasma cells. F, A few were kappa chain-positive plasma cells.

and $10-50 \%$ of intestinal MALT lymphomas. Its oncogenic activity is attributed to overexpression of MALT1, which is an important mediator of activation of the canonical and non-canonical NF- $\mathrm{BB}$ pathways. ${ }^{44-48}$ Other recurrent translocations, more commonly observed at extra-GI sites, have been reported in $<5 \%$ of GI MALT lymphomas in most published series. They include the $\mathrm{t}(14 ; 18)(\mathrm{q} 32 ; \mathrm{q} 21) / \mathrm{IGH}-$ MALT1, $\mathrm{t}(1 ; 14)(\mathrm{p} 22 ; \mathrm{q} 32) / \mathrm{IGH}-B C L 10$, and $\mathrm{t}(3 ; 14)$ (p14.1;q32)/IGH-FOXP1 translocations. ${ }^{49,50}$ In gastric MALT lymphomas, the $t(11 ; 18)(\mathrm{q} 21 ; \mathrm{q} 21)$ translocation is more prevalent in $\mathrm{H}$. pylori-negative cases, correlates with higher-stage disease, and is a factor in the poor response to alkylating agents. ${ }^{51,52}$ Conversely, t(11;18)-positive MALT lymphomas are less prone to transformation to DLBCL. ${ }^{53}$ When it is present in $H$. pylori-positive cases, the $\mathrm{t}(11 ; 18)(\mathrm{q} 21$; q21) translocation is predictive of non-response to or relapse after antibiotic therapy. ${ }^{21,54}$ Therefore, fluorescence in-situ hybridisation (FISH) testing for $\mathrm{t}$ $(11 ; 18)$ is recommended at initial diagnosis or for the cases that fail to respond to anti-H. pylori therapy. ${ }^{30,55}$ The clinical significance of the infrequent IGH-BCL1O rearrangement is not clear, although a small study suggested that cases with $\mathrm{t}(1 ; 14)$ or strong nuclear expression of B-cell lymphoma 10 (bcl-10) most likely do not respond to H. pylori eradication. $^{56}$

Other aberrations variably reported in gastric MALT lymphoma are deletions of TNFAIP $3 / A 20$ (6q23), which encodes an inhibitor of NF- $\mathrm{kB}$, and trisomies/gains of chromosomes 3, 8, and $18 .^{57-60}$

In recent years, a few studies have examined the mutational landscape of MALT lymphomas by means of whole exome sequencing or targeted next-generation sequencing (NGS) technologies. ${ }^{57,61-63}$ Distinct genetic profiles were observed in MALT lymphomas from different sites. ${ }^{63}$ Overall, only a small number of gastric MALT lymphomas have been analysed, with variations in the methodology in the different studies. Recurrent mutations in genes involved in activation of NF- $\mathrm{KB}$ signalling pathways, such as TRAF3 (33\%) and TNFAIP3 $(25 \%)$, were identified, and in general were mutually exclusive with the BIRC3-MALT1 translocation. Interestingly, MALT lymphoma essentially lacks mutations in MYD88, CD79A, or CARD11, which are frequently found in other B-cell 
lymphomas characterised by constitutive NF- $\kappa \mathrm{B}$ activation. Mutations are also found in genes related to B-cell differentiation, notably NOTCH1 (11-25\%), and epigenetic modifications (CIITA, TBL1XR1, and TET2), and in tumour suppressor genes. ${ }^{61}$ Mutations in GPR 34 and PIK3CD, which are frequently found in MALT lymphomas of the salivary glands and thyroid, have not been detected in gastric MALT lymphomas. ${ }^{63}$

\section{Differential diagnosis}

A common diagnostic challenge is differentiating gastric MALT lymphoma from $H$. pylori-associated gastritis. An expansile, destructive infiltrate, the cytological characteristics of the infiltrating cells, Dutcher bodies, infiltration of the muscularis mucosae and prominent lymphoepithelial lesions favour lymphoma, but many biopsies may lack some of these features. Monotypic immunoglobulin expression and/or coexpression of CD43 by the B cells establish malignancy. Morphological assessment with the Wotherspoon scoring system helps in identifying the cases that may benefit from clonality testing. ${ }^{19,64}$

Differentiating MALT lymphoma from other small B-cell lymphomas, notably MCL, which shows tropism for the GI mucosa, but also SLL/chronic lymphocytic leukaemia (CLL) and FL, can also be challenging. Immunohistochemistry is key in establishing the correct diagnosis (see below). Because of the morphological overlap between MCL and MALT lymphoma, cyclin D1 immunohistochemistry should be performed in all cases of GI small B-cell lymphoma. ${ }^{30}$ MALT lymphomas with extensive plasmacytic differentiation should be distinguished from plasma cell neoplasia, either extramedullary plasmacytoma or dissemination of a multiple myeloma, which occur rarely in the GI tract (Figure 4). ${ }^{65}$

Although large cells are typically present and admixed with the small B cells in MALT lymphoma, sometimes representing up to $20 \%$ of the total cells, transformation to DLBCL should be considered when sheets or confluent clusters of large, transformed cells are found outside follicles. Clusters of at least 20 cells or a proportion of $>30 \%$ large cells are needed to consider a diagnosis of large-cell transformation. Conversely, diffusely scattered large cells, representing 5$10 \%$ or even up to $20 \%$ of the total population, are not associated with a worse prognosis, as long as they do not form clusters. ${ }^{66-68}$ If a component of MALT lymphoma is noted in a gastric or intestinal DLBCL, it should be mentioned in the report. Reactive germinal centres in MALT lymphomas, which can be identified by their germinal centre immunophenotype, should not be mistaken as foci of large-cell transformation.

\section{Follow-up biopsies in gastric MALT lymphomas}

Irrespective of stage, H. pylori eradication is the initial treatment of choice, and it is recommended that follow-up biopsies are taken 2-3 months after treatment and subsequently twice yearly for 2 years. ${ }^{30}$ The evaluation of histological response is based on the Groupe d'Etude des Lymphomes de l'Adulte (GELA) scoring system. ${ }^{69,70}$ In this scheme, patients with complete response or probable minimal residual disease, in which small residual lymphoid aggregates are recognised, should be managed with observation and regular follow-up. Although molecular assays have shown that such lymphoid aggregates may harbour the same clonal IG gene rearrangements as the initial lymphoma, molecular testing is not recommended, as no firm correlation has been established between a positive molecular test result and a higher risk of relapse. ${ }^{71-73}$ Patients with responding residual disease or no-change/stable disease can also be managed with observation for several months, as long as they are asymptomatic, because responses may occur as late as $>18$ months after the completion of antibiotic therapy. ${ }^{72,74}$ In patients not responsive to antibiotic therapy or with progressive disease, there are several therapeutic options, including radiation therapy, chemotherapy, and/or immunotherapy. ${ }^{30}$

As higher rates of epithelial preneoplastic lesions (intestinal metaplasia, atrophic gastritis, and dysplasia) and a six-fold increased risk for gastric adenocarcinoma have been reported in patients with gastric MALT lymphoma, ${ }^{75-78}$ it is important, in follow-up biopsies, not only to assess the lymphoid infiltrates but also to screen the biopsies for (pre)neoplastic epithelial lesions.

DU ODENAL-TYPE AND PRIMAR Y INTESTINAL FL

Primary intestinal FL accounts for $5-10 \%$ of primary intestinal lymphomas overall, and affects middle-aged to older adults. Approximately half of the cases occur in the second portion of the duodenum,,$^{1,2,79,80}$ and because these show distinct clinicopathological features - duodenal presentation, low histological grade, indolent behaviour, and excellent outcome - they are now recognised as a distinct disease entity, namely duodenal-type FL. $^{7}$ FL cases developing elsewhere along the GI tract, usually in the small intestine or colon, are referred to as primary intestinal FL (Table 3). Most duodenal-type FL cases are discovered incidentally during upper GI endoscopy for 


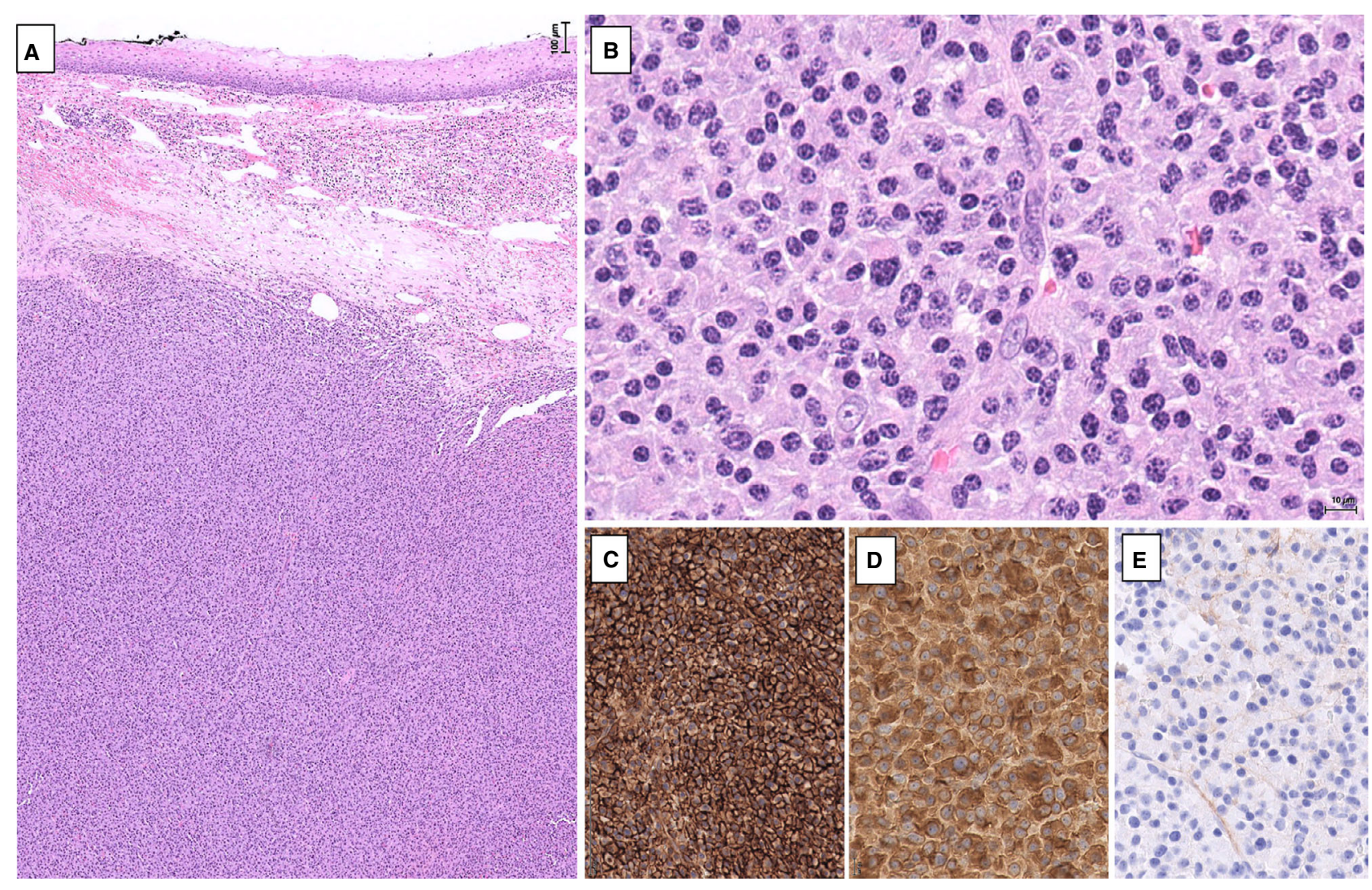

Figure 4. Oesophageal involvement by multiple myeloma. A, A panoramic view showing a dense and diffuse mucosal infiltrate, and the overlying normal epithelium [haematoxylin and eosin (H\&E)]. B, The infiltrate consisted of sheets of plasma cells, ranging from mature to atypical (H\&E). C, Strong and diffuse CD138 positivity. D, Monotypic expression of kappa light chains. E, Absence of immunostaining for lambda light chains.

surveillance of unrelated pathologies, such as gastritis, gastro-oesophageal reflux disease, or other malignancies, and only a minority of patients present with mass effect symptoms such as obstructive jaundice. ${ }^{79,81-83}$ Endoscopically, the lesions appear as one or more nodules or small polyps in the second portion of the duodenum, but multifocal involvement of more distal regions of the intestine, mainly the jejunum, is not uncommon. ${ }^{81,82}$ Duodenal-type FL is an indolent disease for which a watchful waiting approach is generally recommended. ${ }^{82,84}$ Nodal involvement (stage II) is a risk factor associated with progression. ${ }^{85}$ Only a few case reports have documented transformation to DLBCL. ${ }^{86-88}$ Non-duodenal-type FLs tend to produce larger symptomatic tumour masses that may be obstructive or cause bleeding, and staging is essential to differentiate primary intestinal disease from secondary GI involvement by a systemic (nodal) FL.

\section{Pathological features}

In duodenal-type FL (Figure 5A-D), the neoplastic follicles expand the duodenal mucosa/submucosa and show features of grade 1-2 FL, i.e. non-polarised neoplastic follicles composed primarily of centrocytes with few centroblasts, and lacking a starry-sky appearance, an attenuated mantle zone, and infiltration of centrocytes in the lamina propria outside the follicles. The $\mathrm{B}$ cells are $\mathrm{CD} 10+$, bcl-6+, and bcl-2+, with a low Ki67 proliferation index. One characteristic feature of duodenal-type FL is the frequent distribution of $\mathrm{CD} 21+\mathrm{CD} 23+$ follicular dendritic cells at the periphery of the neoplastic germinal centres, referred to as a "hollowed-out' appearance. Furthermore, duodenal-type FL neoplastic cells preferentially express IgA over $\operatorname{IgM},{ }^{89,90}$ and the mucosal homing receptors $\alpha 4 \beta 7$ integrin and CCR9 chemokine receptor, which direct lymphocyte trafficking to the intestinal mucosa. ${ }^{91,92}$

Non-duodenal-type FL (Figure 5E-G) tends to be transmural, encompasses cases ranging from grade 1-2 to grade 3 , and may be accompanied by sclerosis. It is histologically and phenotypically indistinguishable from systemic FL. 
Table 3. Key points in comparison between primary intestinal and duodenal-type follicular lymphoma (FL)

\begin{tabular}{|c|c|c|}
\hline & $\begin{array}{l}\text { Primary intestinal FL } \\
<4 \% \text { of primary } \mathrm{Gl} \\
\text { lymphomas }\end{array}$ & $\begin{array}{l}\text { Duodenal-type FL } \\
<4 \% \text { of primary Gl } \\
\text { lymphomas }\end{array}$ \\
\hline Localisation & $\begin{array}{l}\text { Small and large } \\
\text { intestine } \\
\text { Rare in the stomach }\end{array}$ & $\begin{array}{l}\text { Duodenum (D2) } \pm \\
\text { simultaneous } \\
\text { involvement of the } \\
\text { jejunum or ileum }\end{array}$ \\
\hline Macroscopy & $\begin{array}{l}\text { Infiltrative, usually } \\
\text { transmural } \pm \text { regional } \\
\text { LN involvement } \\
\text { Lymphomatous } \\
\text { polyposis }\end{array}$ & $\begin{array}{l}\text { Polypoid lesions, mucosa } \\
\text { and submucosa, no LN } \\
\text { involvement }\end{array}$ \\
\hline $\begin{array}{c}\text { Presenting } \\
\text { features }\end{array}$ & $\begin{array}{l}\text { Middle-aged (50 years) } \\
\text { Abdominal discomfort, } \\
\text { obstruction, bleeding }\end{array}$ & $\begin{array}{l}\text { Slightly older (60 years) } \\
\text { Asymptomatic (incidental } \\
\text { endoscopic finding) or } \\
\text { abdominal discomfort }\end{array}$ \\
\hline \multirow[t]{2}{*}{ Pathology } & \multicolumn{2}{|c|}{$\begin{array}{c}\text { Centrocytes and centroblasts } \\
\text { CD20+ CD10+ bcl-2+ bcl-6+ } \\
\text { Most cases } \mathrm{t}(14 ; 18)+(\mathrm{IGH}-B C L 2)\end{array}$} \\
\hline & $\begin{array}{l}\text { Grade } 1-2>\text { grade } 3 \\
\text { bcl- } 6 \text { and } C D 10 \text { can be } \\
\text { down-regulated }\end{array}$ & $\begin{array}{l}\text { All cases grade } 1-2 \\
\text { CD21+ FDCs at the } \\
\text { periphery of the } \\
\text { nodules, preferential IgA } \\
\text { expression }\end{array}$ \\
\hline
\end{tabular}

bcl-2, B-cell lymphoma 2; bcl-6, B-cell lymphoma 6; FDC, Follicular dendritic cell; GI, Gastrointestinal; LN, Lymph node.

\section{Molecular genetics}

Both duodenal-type and other intestinal FLs harbour the $\mathrm{t}(14 ; 18)(\mathrm{q} 32 ; \mathrm{q} 21) / \mathrm{IGH}-\mathrm{BCL} 2$ translocation in the majority of the cases. In duodenal-type FL, the active somatic hypermutation machinery is related to the expression of BTB and $\mathrm{CNC}$ homolog 2 (BACH2) instead of activation-induced cytidine deaminase (AID). ${ }^{83,93}$ In an effort to shed light on the molecular differences between duodenal-type FL and nodal FL and explain the indolent clinical behaviour of duodenal-type FL, recent studies analysed the genetic landscape of the neoplastic cells and the expression profile of the immune microenvironment. ${ }^{94,95}$ Comparison of the mutational landscapes of duodenal-type FL and nodal FL showed no significant differences in the mutation rates of the most recurrently altered genes, including CREBBP, TNFRSF14/HVEM, and EZH2. In contrast, duodenal-type FL showed fewer biallelic or multiple mutations in the histone methyltransferase KMT2D/MLL2 gene and a high frequency of mutations in HVCN1 and EEF1A1, in 22\% and $35 \%$ of cases, respectively. ${ }^{94}$ Interestingly, $H V C N 1$ mutations were reported to correlate with longer progressionfree survival in patients with systemic FL. ${ }^{96}$

Conversely, factors related to the microenvironment appear to play a significant role in duodenal-type FL lymphomagenesis. Selective usage of the IGHV4 gene segment in most cases indicates an antigen-driven mechanism of lymphomagenesis. ${ }^{93,97}$ Furthermore, gene expression analyses have shown a distinct immune microenvironment profile in duodenal-type FL, characterised by a chronic inflammation gene signature and overexpression of proinflammatory cytokines and chemokines such as CXCL6, TNFSF15, CCL11, CXCL1, CCL21, and CCL20 with its ligand CCR6, with consequent recruitment of Th17 and activated $\mathrm{CD} 4+\mathrm{T}$-helper cells into the lymphoma microenvironment. ${ }^{94,95}$

M C L

MCL is an aggressive type of B-cell lymphoma, accounting for approximately $3-5 \%$ of primary GI lymphomas. $^{2,98}$ MCL mainly affects elderly and predominantly male individuals. As a primary GI disease, it may present as multiple mucosal polyps, so-called multiple lymphomatous polyposis, more commonly in the lower GI tract. ${ }^{99,100}$ Gastric involvement manifests as large cerebroid folds. Presenting symptoms may include abdominal pain, weight loss, diarrhoea, or bleeding. Staging frequently reveals widespread extraintestinal disease (stage IV). Microscopic GI tract involvement is also extremely frequent (84\%) in patients with systemic MCL. ${ }^{101,102}$

\section{Pathological features}

MCL is composed of a monotonous small to mediumsized lymphoid cell population, with clefted nuclei, indistinct nucleoli, and scant cytoplasm, that infiltrates the mucosa and submucosa in a nodular or diffuse fashion (Figure 6). Occasionally, infiltration of epithelial structures is found, resembling lymphoepithelial lesions. ${ }^{103}$ Two aggressive cytological variants are recognised, namely blastoid and pleomorphic. Immunophenotypically, the cells typically express CD20, PAX5, CD5, CD43, IgD, bcl-2, and cyclin D1, and are negative for CD23, CD10, and bcl-6. Rare cases with aberrant phenotypes, namely CD5-, CD10+, or bcl-6+, have been described. SOX11 expression is a useful diagnostic marker in the rare cyclin D1- MCL cases. ${ }^{104}$ A Ki67 proliferation index of $>30 \%$ identifies patients with a poor prognosis, and should be reported. ${ }^{7}$ 

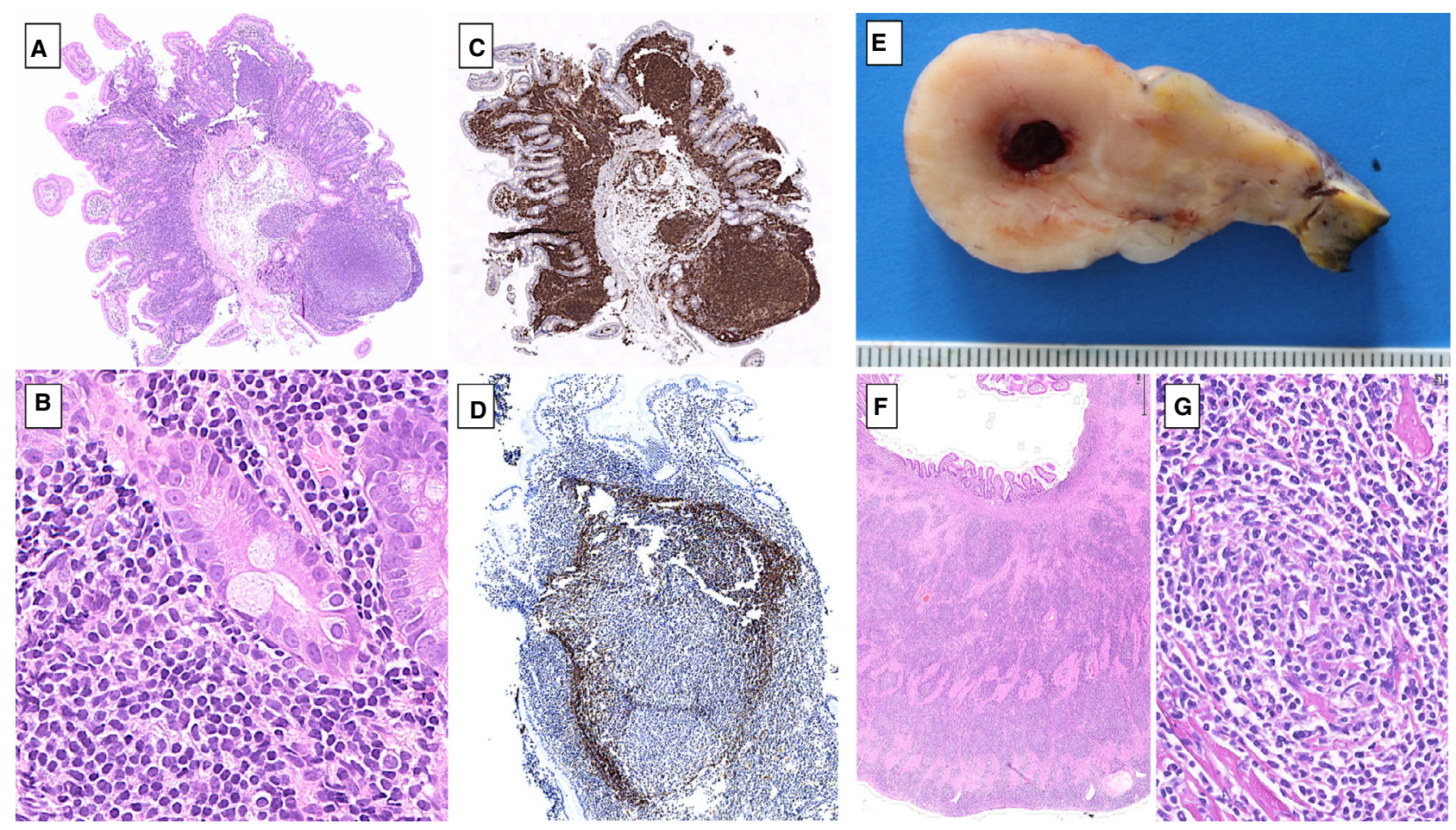

Figure 5. Intestinal follicular lymphoma. A-D, Duodenal-type follicular lymphoma. A, The lesion presented as a mucosal polyp with nodular and partly diffuse involvement of the lamina propria [haematoxylin and eosin (H\&E)]. B, Cytologically, most cells were small, resembling centrocytes (H\&E). C, Diffuse positivity for B-cell lymphoma 2 (bcl-2). D, CD21 immunostaining showing follicular dendritic-cell meshworks pushed to the outer rim of the follicles. E-G, Primary follicular lymphoma of the small intestine. E, The lesion presented as a circumferential and transmural infiltrate causing obstruction, and required surgical excision. F, A panoramic view of the intestinal wall involved by the lymphoma infiltrate (H\&E). G, Neoplastic follicles associated with sclerosis, comprising in this case mostly centrocytes (H\&E).

\section{Molecular genetics}

The characteristic genetic signature of MCL is the $\mathrm{t}$ $(11 ; 14)(\mathrm{q} 13 ; \mathrm{q} 32)$ translocation resulting in $\mathrm{IGH}_{-}$ CCND1 fusion and cyclin D1 overexpression, whereas cases that lack cyclin D1 expression often show alternative CCND2 or CCND3 rearrangements. ${ }^{105,106}$ Immunogenetic studies have shown a biased usage of certain IGHV genes (IGHV3-21, IGHV4-34, IGHV1-8, and IGHV3-23), suggesting antigen-driven selection, whereas completely unmutated IGHV genes are detected in $\sim 30 \%$ of the cases, which have a worse prognosis than cases with IGH somatic hypermutations. ${ }^{107,108}$ The genomic landscape of MCL is heterogeneous, and comprises mutations in genes involved in DNA damage response (ATM and TP53) and Notch signalling (NOTCH1 and NOTCH2), and in genes affecting RNA metabolism and splicing (EWSR1, DAZAP1, and HNRNPH1). Mutations in TP53, SMARCA4, CELSR3, CCND1 and KMT2D have been found to negatively affect the response to venetoclax-based therapies. ${ }^{109-111}$
The median survival is 3-5 years, and the majority of cases remain incurable, with multiple relapses. Besides standard chemotherapy, treatment options currently comprise many new drugs such as ibrutinib, lenalidomide, bortezomib, temsirolimus, and venetoclax. ${ }^{112}$

S L L

Although rare cases of primary SLL of the GI tract have been described, ${ }^{113}$ most of them represent secondary involvement in patients with known CLL. It usually consists of a dense and diffuse infiltrate of small round lymphocytes, which may constitute proliferation centres. The lymphoma cells are CD20+ (often with heterogeneous or weak expression), CD5+, CD23+, CD43+, cyclin D1-, and lymphoid enhancer binding factor 1 (LEF1)+. ${ }^{114,115}$ Secondary lymphoid follicles or lymphoepithelial lesions typical of MALT lymphoma are usually not seen. 

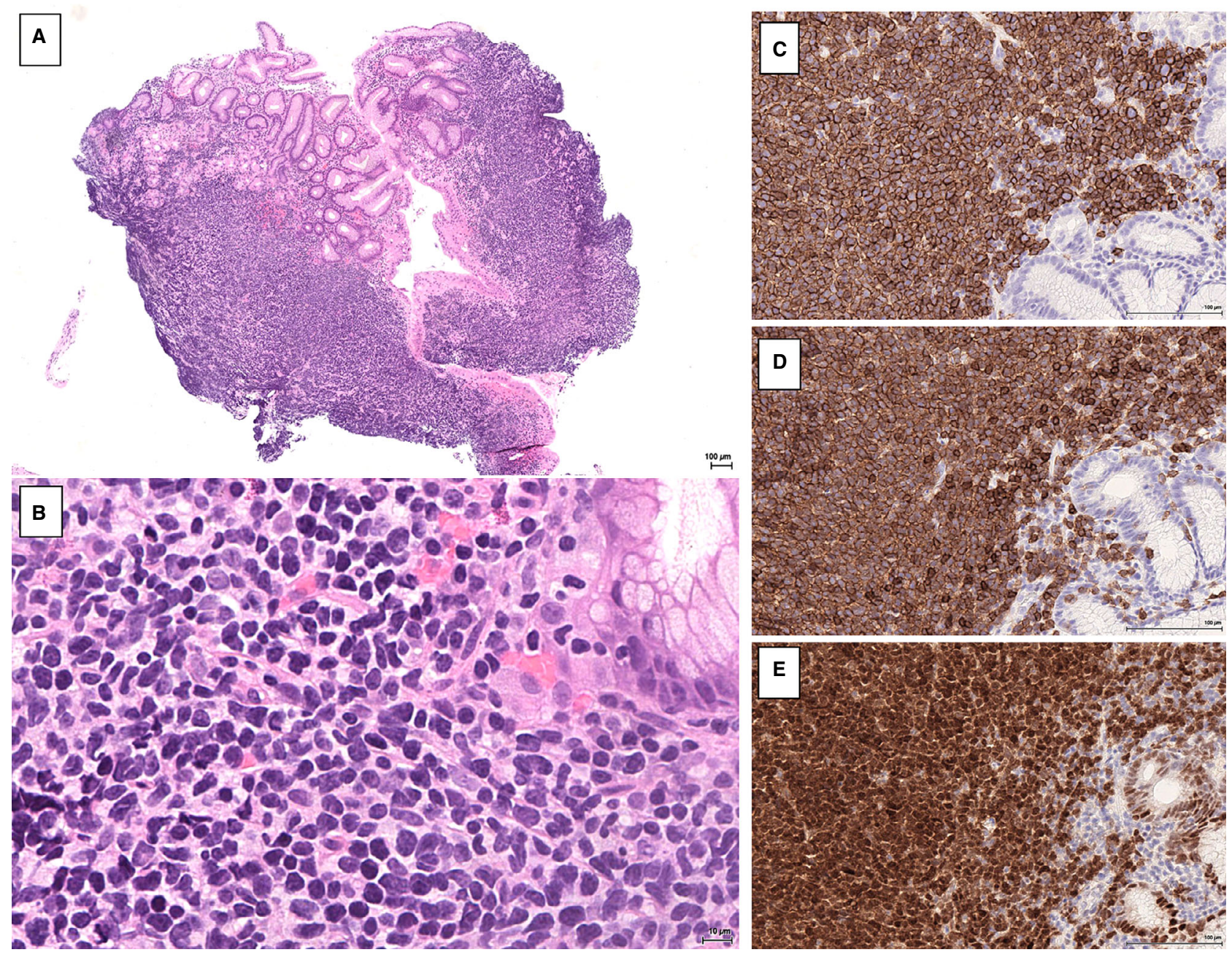

Figure 6. Mantle cell lymphoma of the stomach. A, A panoramic view showing a dense basophilic lymphoid infiltrate [haematoxylin and eosin (H\&E)]. B, A monotonous infiltrate of small cells with irregular nuclei, adjacent to a residual gastric gland (H\&E). C, CD20 positivity. D, CD5 expression. E, Cyclin D1 nuclear positivity.

\section{Aggressive B-cell lymphomas}

DLBCL, including the not otherwise specified (NOS) type (DLBCL, NOS) and specific variants, is the most common aggressive lymphoma of the upper GI tract. $^{2-6}$ Burkitt lymphoma (BL) and high-grade B-cell lymphomas (HGBCLs) occur less frequently. Two HGBCL entities were created in the revised WHO classification of lymphoid neoplasms, to classify a group of aggressive B-cell lymphomas that are clinically and biologically distinct from DLBCL, NOS and BL. HGBCLs with $M Y C$ and BCL2 and/or BCL6 rearrangements [so-called double-hit (DH) or triple-hit (TH) lymphomas; HGBCL-DH/TH] are defined by their genetic features, irrespective of the morphology. HGBCL, NOS encompasses cases previously termed 'unclassifiable, with features intermediate between DLBCL and BL', or showing blastoid morphology, but lacking DH/TH translocations. ${ }^{7,116}$

The current diagnostic approach to aggressive lymphomas of B-cell lineage according to the 2017 WHO guidelines is summarised in Figure 7. The first level of assessment remains cytomorphology, which encompasses large cells (centroblastic, immunoblastic, plasmablastic or anaplastic types), Burkitt-type morphology (monomorphic medium-sized cells with basophilic cytoplasm, coarse chromatin and several medium-sized nucleoli, densely packed and associated with a starry-sky pattern), intermediate cases (comprising somewhat pleomorphic cells with features intermediate between Burkitt cells and large cells, often featuring prominent apoptosis and a starry-sky 


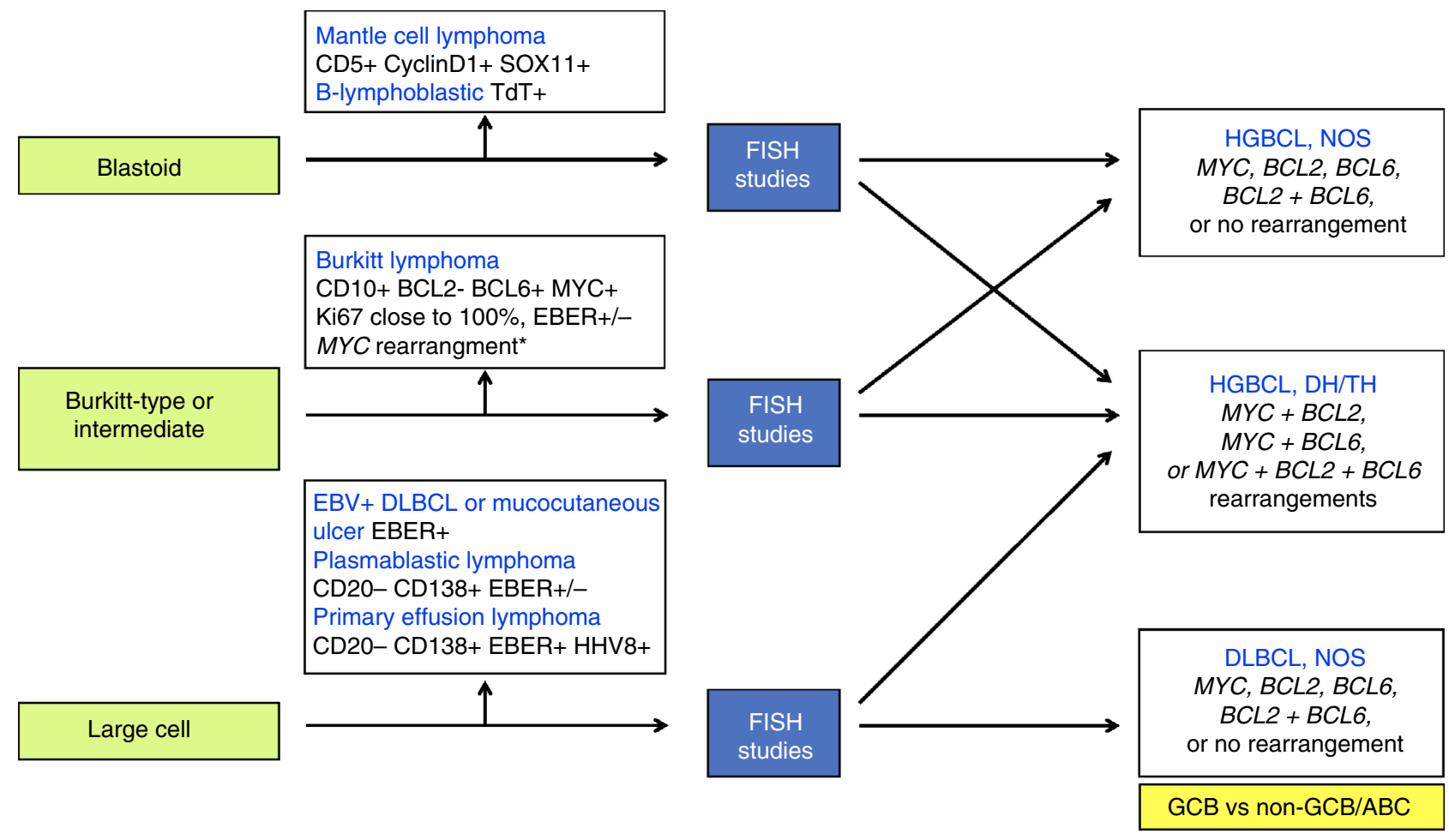

Figure 7. The diagnostic approach to high-grade B-cell lymphomas. ABC, activated B-cell-like; GCB, germinal centre B-cell-like; HGBCL-DH/ TH, high-grade B-cell lymphoma with MYC and BCL2 and/or BCL6 rearrangements (double-hit/triple-hit). HGBCL, NOS, high-grade B-cell lymphoma, not otherwise specified. *Demonstration of a MYC rearrangement may not be mandatory in cases with typical morphology and immunophenotype.

pattern), and blastoid tumours (comprising mediumsized cells with fine chromatin, indistinct nucleoli, and scant cytoplasm). Cases with blastoid morphology may represent blastoid MCL or lymphoblastic neoplasms, which are best identified with an appropriate panel of immunostains. BL is a rather uniform entity, and in cases with typical morphology the diagnosis is confirmed by the demonstration of the expected immunophenotype $(\mathrm{CD} 20+\mathrm{CD} 10+$ bcl2- bcl-6+ MYC+, and a Ki67 proliferation close to $100 \%$ ), and association with Epstein-Barr virus (EBV) infection in a subset of the cases. In cases with typical morphology and immunophenotype, confirmation of a MYC rearrangement by the use of FISH is optional; in cases showing deviations from the typical features (mild cytological pleomorphism and bcl-2 expression), FISH studies are mandatory to assess the MYC status and exclude a DH lymphoma (Figure 8). The majority of lymphomas composed of large B cells remain under the umbrella term of DLBCL, NOS. However, specific entities that may occur as GI neoplasms, such as $\mathrm{EBV}+$ entities $(\mathrm{EBV}+\mathrm{DLBCL}$ and $\mathrm{EBV}+$ mucocutaneous ulcer), plasmablastic lymphoma, and the solid form of primary effusion lymphoma, have to be excluded, and FISH studies are also mandatory to identify the small subset of large B-cell lymphomas with MYC and BCL2 and/or BCL6 rearrangements, because these are classified as HGBCL-DH/TH. ${ }^{7}$

DLBCL, NOS

DLBCL, NOS usually presents de novo, but some cases represent transformation of a pre-existing systemic or GI small B-cell lymphoma. ${ }^{5,6}$ In particular, transformation of systemic FL may occur in the small intestine, whereas MALT lymphoma represents the most common primary GI small B-cell lymphoma that undergoes transformation to DLBCL. DLBCL usually presents as symptomatic ulcerated tumour masses or mucosal thickening. The majority of cases are localised (stage I or II) at diagnosis. ${ }^{117-119}$ The tumour is composed of large or medium to large lymphoid cells, with centroblastic and/or immunoblastic and, less commonly, anaplastic morphology. The growth is diffuse and obliterates the crypts or glands without the formation of typical lymphoepithelial lesions. A smallcell component may be present in transformed cases, 

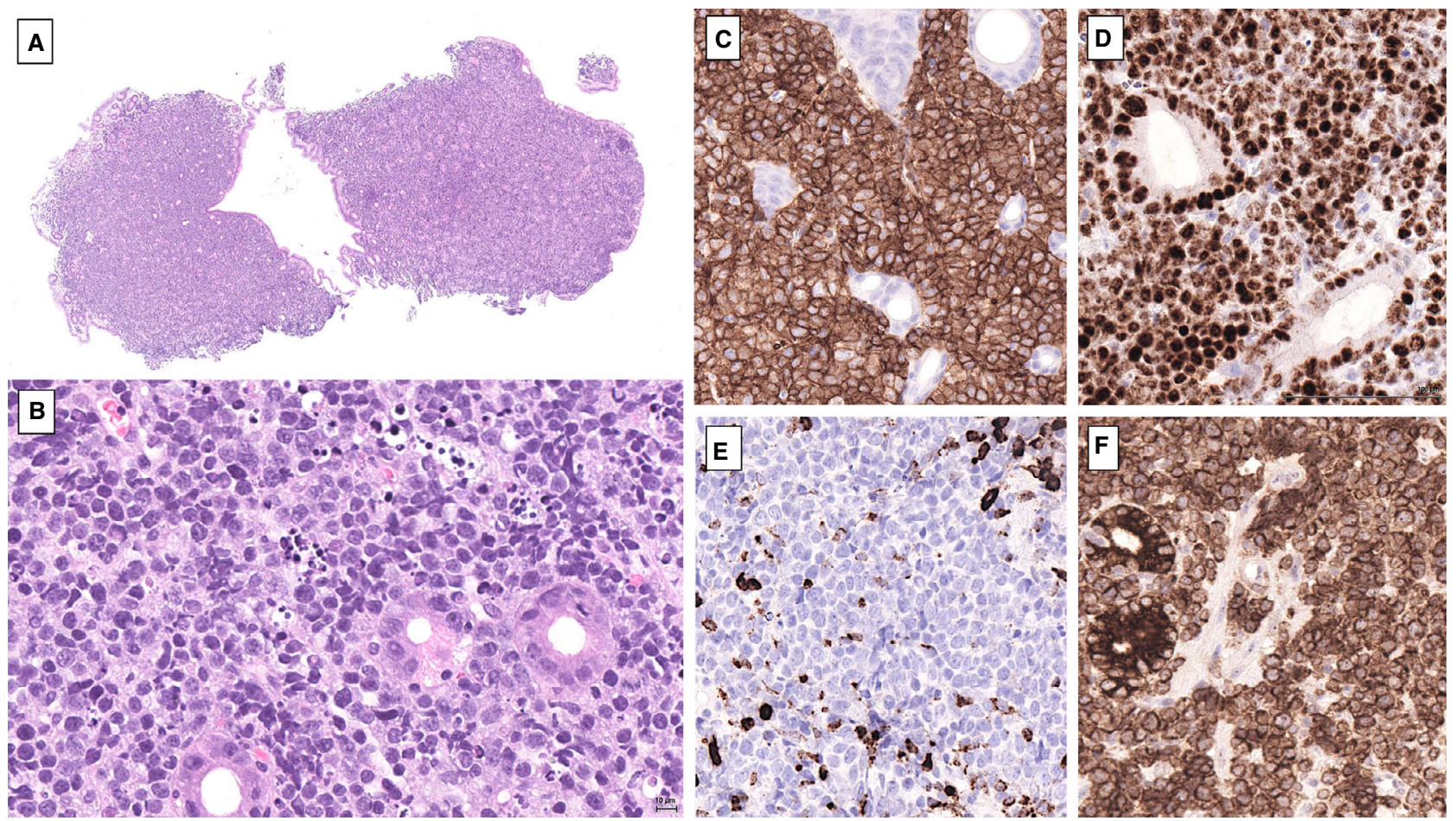

Figure 8. High-grade B-cell lymphoma with concomitant rearrangement of MYC and BCL2 (double-hit lymphoma). A, A low-power view showing a diffuse mucosal basophilic infiltrate [haematoxylin and eosin (H\&E)]. B, Cytomorphology was intermediate between medium and large cells, with a focal starry-sky pattern (H\&E). C, Strong CD10 positivity. D, The Ki67 proliferation index was very high. E, Lack of B-cell lymphoma 2 (bcl-2) expression as shown by use of the usual Dako antibody (clone 124). F, Conversely, the clone E17 bcl-2 antibody demonstrated diffuse bcl-2 expression. This pattern was probably due to a BCL2 mutation interfering with immunoreactivity of the epitope recognised by the Dako clone 124 antibody.

and the presence of residual follicular dendritic cell meshworks may denote an underlying MALT lymphoma. The lymphoma cells express pan-B-cell antigens (CD20, CD19, CD22, CD79a, and PAX5) and monotypic surface and/or cytoplasmic immunoglobulin, usually IgM, and rarely coexpress CD5. ${ }^{118} \mathrm{~A}$ subset of gastric DLBCLs are associated with $H$. pylori infection, and there have been sporadic case reports and one prospective study suggesting that H. pylori eradication might be an effective treatment for limited-stage de-novo $H$. pylori-positive gastric DLBCLs. ${ }^{120-122}$ In a recent retrospective study from China, it was found that a positive $H$. pylori status in gastric DLBCL was associated with a higher proportion of stage I-II disease and was a predictor of less aggressive behaviour and better outcome. ${ }^{117}$ It is mandatory, according to WHO recommendations, that DLBCL, NOS be classified into 'germinal centre B-cell-like (GCB)' and 'non-GCB' or 'activated B-celllike (ABC)' subtypes. ${ }^{7}$ In diagnostic practice, this is usually achieved by means of immunohistochemical algorithms designed as surrogates of mRNA-based expression signatures. The Hans classifier, based on the assessment of three markers (CD10, bcl-6, and MUM1) is one of the most widely used. ${ }^{123}$ Other alternatives incorporating other markers, such as FOXP1 and/or GCET-1, have been proposed. ${ }^{124}$ Methods based on mRNA expression profiling that are applicable to routinely processed samples are also available, e.g. the Lymph2Cx assay or multiplex ligation-dependent probe amplification (MLPA) assay, but they are less widely used. ${ }^{125,126}$ In the stomach, the non-GCB/activated cases outnumber tumours with a GCB immunophenotype $(58-70 \%$ versus 30 $42 \%)^{68,117,118,127,128}$; conversely, intestinal DLBCLs are more often of the GCB type. ${ }^{129-131}$ Those transformed from MALT lymphomas are more often CD10- and bcl-2- than are de-novo DLBCLs, but usually express bcl- $6 .{ }^{26,127,132}$ The diagnostic work-up of DLBCL, NOS should also include the assessment of bcl-2 and MYC expression, with positive cut-offs set at $50 \%$ of cells with cytoplasmic bcl-2 expression and $40 \%$ with MYC+ nuclei. Many cases are immunohistochemically bcl-2+ or MYC+ in the absence of BCL2 

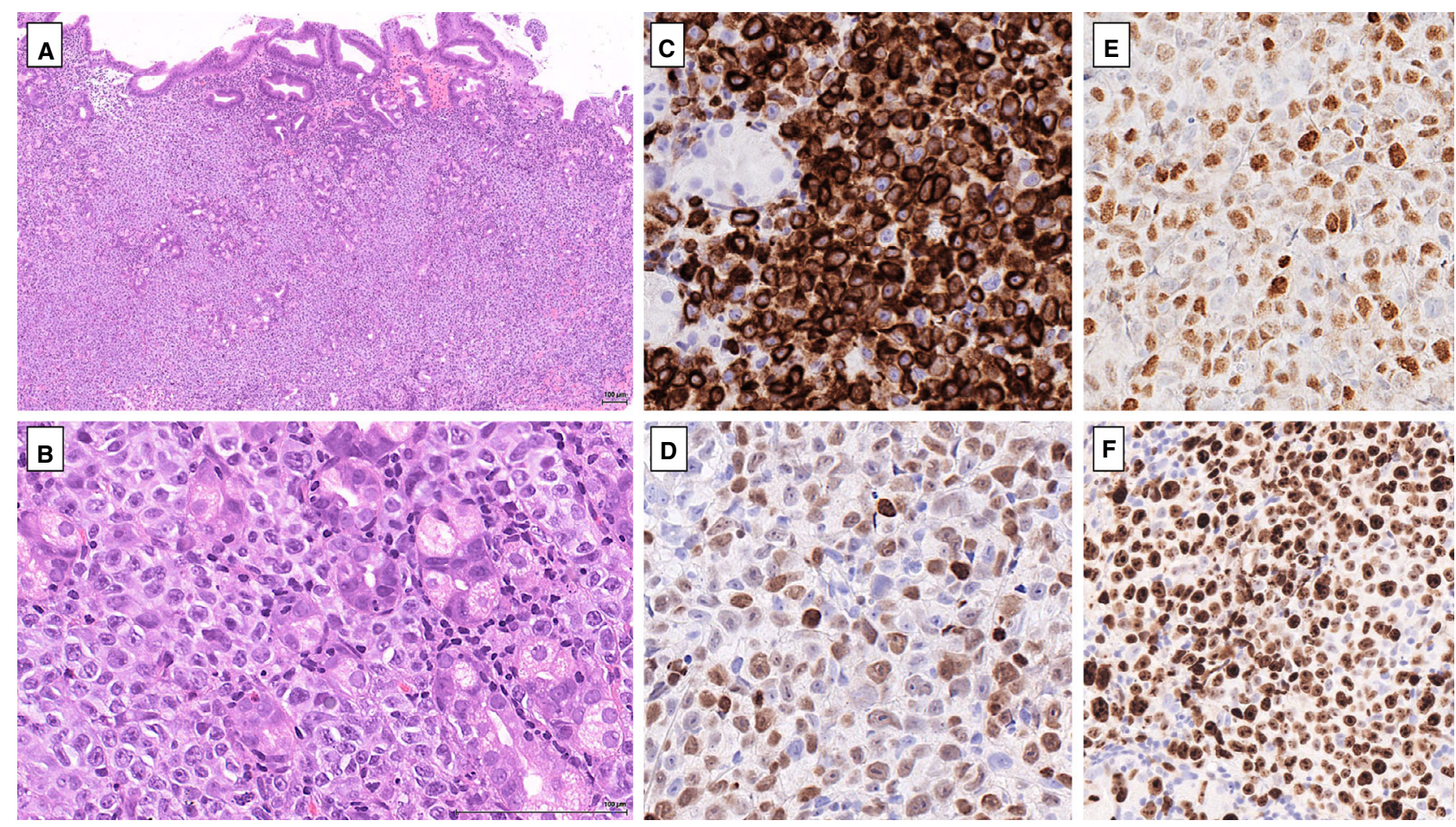

Figure 9. Gastric diffuse large B-cell lymphoma, not otherwise specified. A,B, Diffuse mucosal infiltrate comprising large lymphoid cells [haematoxylin and eosin (H\&E)]. C, Strong B-cell lymphoma 2 (bcl-2) expression. D, MUM1 positivity in the majority of nuclei (this case had an overall activated B-cell-like immunophenotype). E, Nuclear positivity for MYC was present in the majority of nuclei. F, The Ki67 proliferation index was high.

or MYC rearrangements. Importantly, the so-called 'double-expressor' bcl-2+/MYC+ status (Figure 9) identifies a group of patients who have more aggressive disease and poorer outcomes. ${ }^{133,134}$

Although a subset of primary gastric DLBCLs arise by transformation of MALT lymphomas, specific translocations associated with MALT lymphoma, such as the $\mathrm{t}(11 ; 18) / B I R C 3-M A L T 1$ translocation, are rare in DLBCLs, supporting the view that these cases are less prone to transform. ${ }^{135}$ Regarding the recurrent translocations associated with DLBCL, BCL2 rearrangements are overall rarely found in primary GI DLBCL, and $\sim 10 \%$ carry MYC translocations, which is similar to the rate in nodal cases. ${ }^{136-139}$ BCL6 rearrangements, which have been found in association with transformation of MALT lymphoma, are present in $48 \%$ of gastric DLBCLs and 30\% of intestinal DLBCLs. ${ }^{132,139}$ Some studies suggest that BCL6 rearrangements may be associated with a better prognosis. ${ }^{127,140}$ Recently, two seminal studies using a multiplatform genomic approach, consisting of gene expression profiling, whole exome sequencing, structural variants, and DNA copy number analysis, led to the identification of several genetic subgroups based on enrichment of driver mutations and signalling pathways. ${ }^{141,142}$ Interestingly, both studies identified a genetic subgroup defined by the association of structural alterations of BCL6 and NOTCH2 mutations, encompassing both non-GCB and GCB gene expression signatures, which may be related to marginal zone lymphomas.

\section{EBV-ASSOCIATED DISEASES}

A variety of large B-cell lymphoma entities are characterised by a more or less frequent association with EBV infection (Table 4). ${ }^{7}$ Overall these entities are rare, but may involve the GI tract. They have in common the tendency to occur in individuals with some dysfunction of the systemic or local immune system. Given the spectrum of EBV-associated entities, the relevance of EBV testing for proper diagnosis, and the clinical importance of recognising EBV-associated entities, we advocate performing EBV testing by means of in-situ hybridisation for EBV-encoded small RNAs (EBERs) in a broad range of settings. 
Table 4. Epstein-Barr virus (EBV)-associated B-cell lymphoproliferations

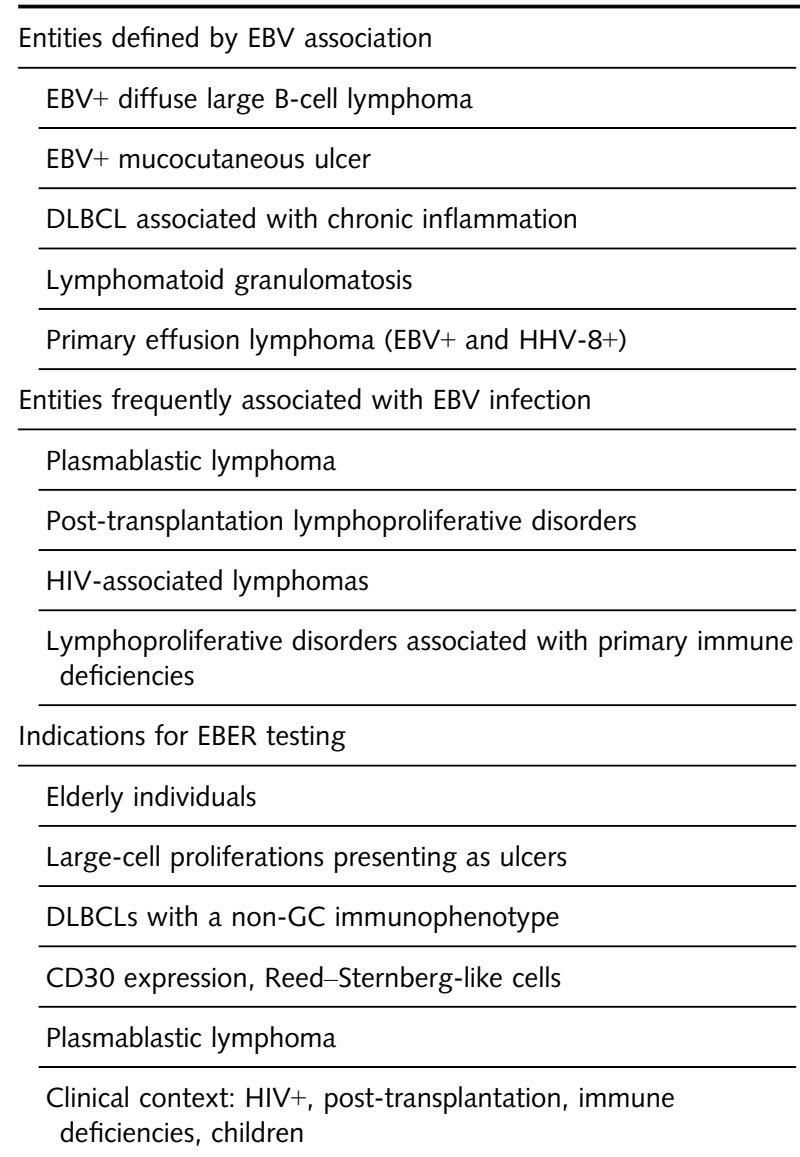

DLBCL, Diffuse large B-cell lymphoma; EBER, Epstein-Barr virusencoded small RNA; GC, Germinal centre; HHV-8, Human herpesvirus 8; HIV, Human immunodeficiency virus.

EBV+ DLBCL, NOS (Figure 10) and EBV+ mucocutaneous ulcer include a broad range of clinicopathological features, ranging from highly aggressive diseases to self-limited localised conditions, with some overlap between the two entities. ${ }^{143}$ The lesions contain EBV+ CD20+ large cells, often including scattered Reed-Sternberg-like cells, and a polymorphic inflammatory background. The immunophenotype is usually of the activated B-cell type, with frequent CD30 expression, but a subset of cases are $\mathrm{CD} 10+{ }^{144} \mathrm{EBV}+$ DLBCL, NOS is generally reported in patients without any known immune deficiency disorder (after exclusion of 'specific' types of EBV+ DLBCL, such as plasmablastic lymphoma), and can occur at any age, but usually in older adults. In a series from Asia, EBV+ DLBCLs represented approximately $7-10 \%$ of gastric primaries, and the presence of EBV was negatively correlated with outcome. ${ }^{119} \mathrm{EBV}$ positivity was found to correlate with higher expression of programmed death-ligand 1 (PD-L1) in the tumour microenvironment, a finding that might have therapeutic impact in the immunotherapy era. ${ }^{118} \mathrm{EBV}+$ mucocutaneous ulcer causes superficial ulcerative lesions in the skin or mucosae in elderly individuals, in the setting of iatrogenic immunosuppression (methotrexate, azathioprine, cyclosporine, mycophenolate) for rheumatoid arthritis or inflammatory bowel disease, in human immunodeficiency virus (HIV)-infected individuals, or post-transplantation. ${ }^{145-147}$ Whereas $\mathrm{EBV}+$ mucocutaneous ulcer has a predilection for the lower GI tract, a recent study from Japan reported that GI EBV+ DLBCLs occurring in non-immunosuppressed individuals have a predilection for the stomach, which was the main localisation of disease for low-stage lesions and was often involved in cases with multifocal lesions. ${ }^{144}$

Plasmablastic lymphoma is composed of large cells, ranging from immunoblasts to plasmablasts with or without a component of mature plasma cells, and is characterised by extinction of the B-cell transcription programme and a plasma cell immunophenotype. ${ }^{148}$ Recent data provide evidence that the transcriptome of plasmablastic lymphoma is more closely related to that of multiple myeloma than to that of other B-cell malignancies. ${ }^{149}$ The GI tract is the most common site of presentation, after the oral cavity, and $\sim 50 \%$ of primary GI plasmablastic lymphomas are diagnosed in the stomach or proximal small intestine. ${ }^{150-153}$ Although plasmablastic lymphoma was initially described in HIV+ individuals, the majority of cases nowadays occur in HIV- patients with other causes of immunosuppression or apparently immunocompetent. ${ }^{151,154,155}$ Plasmablastic lymphoma is essentially negative for CD45, CD20, and PAX5, negative or variably positive for CD79a, and positive for CD38, CD138, and VS38c, with expression of the transcription factors PRDM1/BLIMP-1, MUM1, and XBP1. Epithelial membrane antigen (EMA) and CD30 are also commonly expressed. Cytoplasmic immunoglobulin is detected in $50-70 \%$ of the cases, and CD56 is variably expressed. ${ }^{150,151,153}$ Approximately half of the cases are EBV+ (EBER+; Epstein-Barr nuclear antigen 1 (EBNA1)+). ${ }^{150,151,153}$ MYC rearrangements are found in $50 \%$ of the cases, usually with an IG gene as the translocation partner. ${ }^{151-153,156}$ Recent NGS-based studies have reported recurrent mutations affecting the JAK-STAT (STAT3, JAK1, SOCS1, JAK2, and PIM1), RAS-mitogen-activated protein kinase (MAPK) (NRAS, KRAS, BRAF, and MAP2K1) and Notch (NOTCH1, SPEN, and NCOR2) signalling pathways, providing the genetic basis for new therapeutic interventions. ${ }^{149,157}$ 

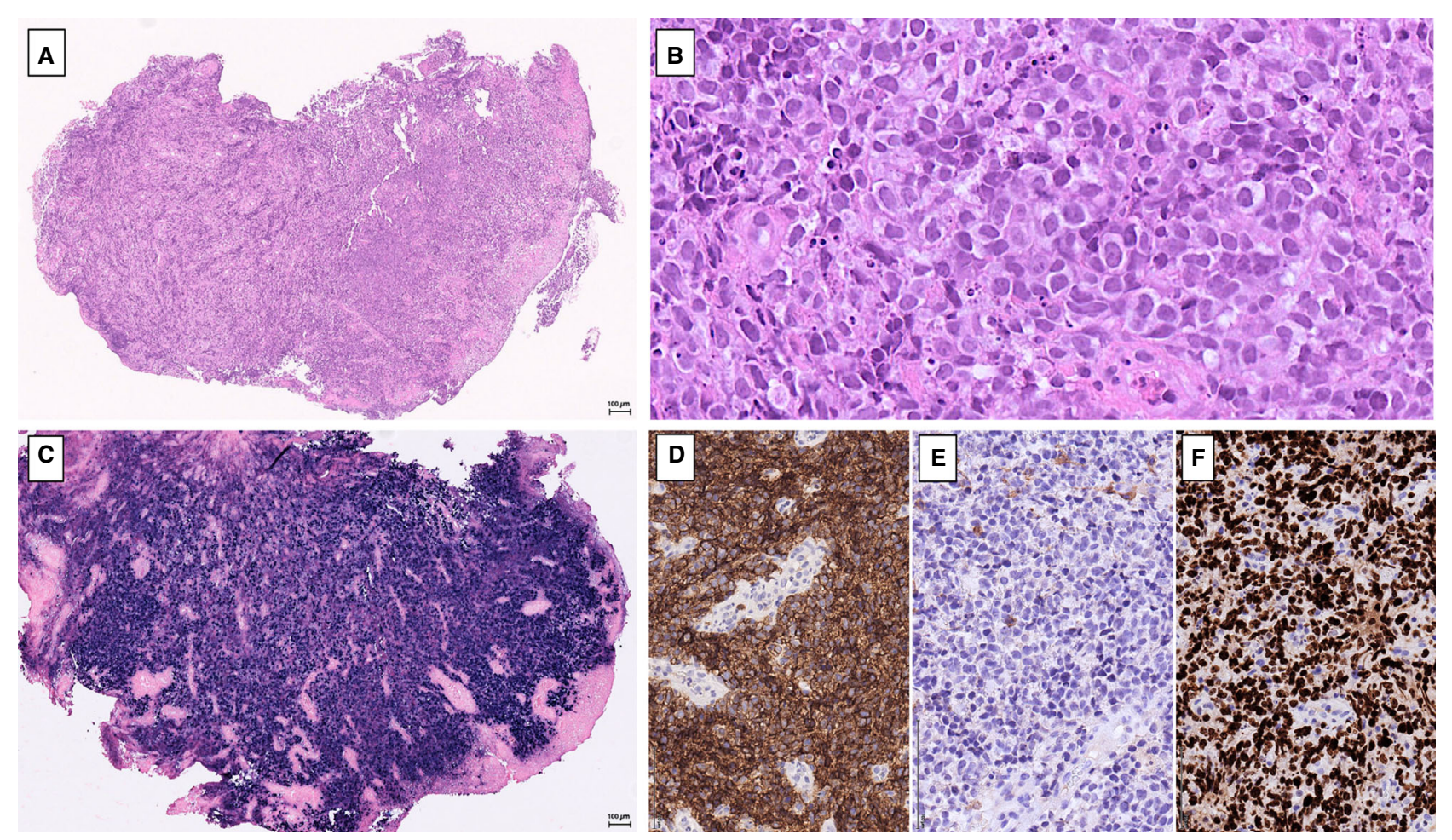

Figure 10. Epstein-Barr virus (EBV)-positive diffuse large B-cell lymphoma, not otherwise specified. A, Diffuse involvement of the gastric mucosa by an ulcerated eosinophilic lymphoproliferation [haematoxylin and eosin (H\&E)]. B, A high-power view showing medium-sized to large lymphoid cells with fine chromatin, and nucleoli, associated with single-cell necrosis and apoptosis (H\&E). C, EBV-encoded small RNA (EBR) in-situ hybridisation was positive in most cells. D, Strong positivity for CD20. E, Lack of CD10 expression. F, A Ki67 proliferation index of $>90 \%$.

\section{T-cell neoplasms}

GI T-cell neoplasms are overall markedly less frequent than B-cell lymphomas, but they encompass several distinct entities. Although the majority of the cases develop in the intestine, a small proportion of the cases may arise in or disseminate to the stomach, duodenum or, uncommonly, oesophagus. The recently revised WHO classification introduced significant changes in the classification of intestinal T-cell lymphomas. The two subtypes of enteropathy-associated T-cell lymphoma (EATL), types I and II, which were previously considered to be variants of the same disease, have been reclassified as two distinct diseases [EATL, formerly type I EATL, and monomorphic epitheliotropic intestinal T-cell lymphoma (MEITL), formerly type II EATL], owing to differences in their epidemiology and clinical features, morphology, phenotype, and genetic features, as highlighted in recent studies. ${ }^{7,158,159}$ Intestinal T-cell lymphoma, NOS is a novel category created to include the cases of primary intestinal T-cell lymphoma not meeting the criteria for either EATL or MEITL. In addition, indolent T-cell lymphoproliferative disorder of the GI tract (ITLDP) represents a newly recognised group of clonal monomorphic proliferations of small $\mathrm{T}$ cells showing a superficial/mucosal distribution along the GI tract, and usually characterised by indolent behaviour and a chronic relapsing course. ${ }^{160,161}$ NK-cell enteropathy (NKCE) represents another rare indolent disorder derived from NK cells. Other mature T/NK-cell lymphoma entities, such as extranodal NK/T-cell lymphoma, nasal type (ENKTCL), can also primarily or secondarily involve the GI tract, and their diagnosis may be challenging.

\section{E A T L}

EATL, the most common form of primary intestinal T-cell lymphoma, is a neoplasm derived from intraepithelial T cells, and occurs in individuals with coeliac disease (CD) (gluten-sensitive enteropathy). The prevalence is highest in Europe, and especially northern Europe, whereas the disease is essentially non-existent in Asia. ${ }^{162-165}$ The median age at presentation is $>60$ years. Patients typically have a history of CD or refractory $\mathrm{CD}(\mathrm{RCD})$, but a substantial proportion of the cases arise de novo, and these may be 
associated with a better outcome. Patients with EATL present with GI symptoms that often culminate in intestinal perforation and peritonitis, or obstruction. B symptoms are common (30-40\%). EATL most commonly affects the small bowel, and rarely the large intestine or stomach ( $8 \%$ of the cases). ${ }^{163,164}$ Lesions are frequently multifocal. The prognosis is poor, with a median survival of 7 months. ${ }^{166}$

\section{Pathological features}

EATL (Figure 11) presents as ulcerative lesions or tumour masses. Histologically, EATL is composed of pleomorphic, medium-sized to large, occasionally anaplastic, lymphoid cells with a high mitotic rate. A mixed inflammatory infiltrate is typically present, usually rich in histiocytes and eosinophils, and may sometimes obscure the lymphoma cells. ${ }^{8}$ Angiocentricity and angioinvasion can lead to extensive necrosis. Enteropathic features [villous atrophy, crypt hyperplasia, and increased intraepithelial lymphocytosis (IEL)] may be seen in the adjacent or distant mucosa. The neoplastic cells are $\mathrm{CD} 2+\mathrm{CD} 3+\mathrm{CD} 4-\mathrm{CD} 5-\mathrm{CD} 7+\mathrm{CD} 8-/+$ CD56- with an activated cytotoxic phenotype and a high Ki67 index. CD30 is usually expressed by a large proportion of cells. ${ }^{167}$ The majority of the cases are negative for T-cell receptor (TCR) expression ('TCR-silent'); $\sim 25 \%$ are positive for $\mathrm{TCR} \alpha \beta$, and TCR $\gamma \delta$ expression has been described in a few cases. Expression of CD103 (human mucosal lymphocyte antigen 1, integrin $\alpha \mathrm{E} \beta 7$ ), which is found in normal intraepithelial lymphocytes, is often at least partially preserved. Overexpression of p53 is seen in many cases.

\section{Molecular and genetic features}

Clonal T-cell receptor (TR) gene rearrangements are detected in the majority of the cases. ${ }^{168-170}$ EATL shows multiple chromosomal imbalances: $9 \mathrm{q}$ gains and almost mutually exclusive losses at 16q12.1, gains of chromosome 7, frequent gains of chromosomes $1 \mathrm{q}$ and $5 \mathrm{q}$, and losses involving 8p22-23.2, 16q21.1, 11q14.1-q14.2, and 9p21.2-p21.3. ${ }^{158,171-}$ 175 The mutational landscape of EATL is characterised by recurrent activating mutations in genes of the JAK-STAT pathway, most commonly JAK1 and STAT3, and rarely JAK3, STAT5B, TYK2, and SOCS1. ${ }^{158,159,176}$ Mutations in genes of the MAPK

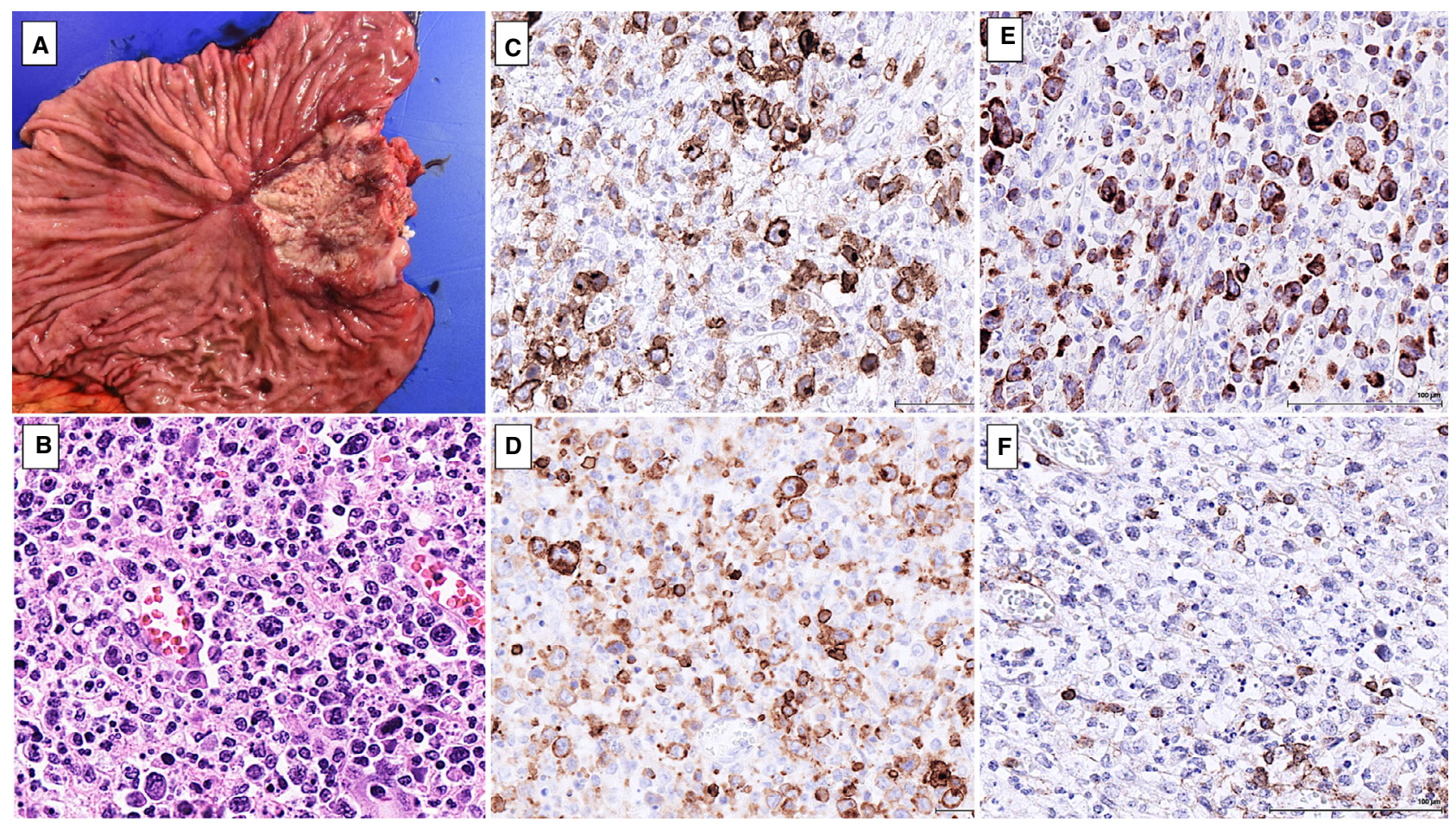

Figure 11. An enteropathy-associated T-cell lymphoma presenting as a subcardial gastric ulcer. A, A macroscopic view of the gastrectomy specimen showing a large, ulcerated subcardial lesion. B. The tumour consisted of a pleomorphic, predominantly large-cell, lymphoid infiltrate, including cells with anaplastic-type morphology (haematoxylin and eosin). C, Strong CD7 expression. D, CD30 positivity was detected in most cells. E, An activated cytotoxic phenotype highlighted by perforin expression. F, Lack of T-cell receptor (TCR)- $\beta$ F1 expression in the neoplastic cells (in contrast to the few reactive lymphocytes in the field) (TCR $\delta$ was also negative in this case, which was overall TCR-silent). 
pathway (KRAS, NRAS, and BRAF) are present in $20 \%$ of the cases, and TP53 mutations have been reported in $10-15 \%$ of the cases. Alterations in SETD2 are less common than in MEITL.

Whole transcriptome sequencing showed differences in the gene expression profiles of EATL and MEITL, further supporting their reclassification as distinct entities. ${ }^{158}$ Genes expressed at higher levels in EATL include STAT3, STAT5A, IRF1/4, and TGM2, which encodes transglutaminase 2, a known autoantigen in $\mathrm{CD}$, highlighting the association of EATL with this disorder. Furthermore, EATL was also characterised by overexpression of interferon- $\gamma$ signalling pathway genes, a pattern reported in untreated $\mathrm{CD}$ patients. ${ }^{177}$

\section{Differential diagnosis}

The diagnosis of EATL in the upper GI tract may be challenging, especially that of de-novo cases if enteropathic features are not identified. In those instances, if the pathological findings are consistent, a diagnosis of EATL should be proposed, and tested with serological investigations and human leukocyte antigen genotyping. In cases with no evidence of $\mathrm{CD}$, a diagnosis of intestinal T-cell lymphoma, NOS is more appropriate. Cases with an anaplastic large-cell morphology and strong CD30 expression may histologically resemble anaplastic large-cell lymphoma (ALCL), but primary intestinal ALCL is very rare, and this diagnosis can be considered only after thorough clinical investigation to exclude underlying CD.

A clinical context of RCD may raise the differential diagnosis between EATL and type II RCD. Type II RCD features villous atrophy and intraepithelial expansion of slightly atypical lymphocytes, which are usually monoclonal and immunophenotypically abnormal, similar to that found in EATL, including loss of surface $\mathrm{CD} 3$ expression by flow cytometry, and loss of CD4 and CD8 expression. However, type II $\mathrm{RCD}$ is an 'in-situ' precursor to EATL, lacking the inflammatory background, predominantly large-cell morphology, infiltration with possible mass formation, necrosis and angioinvasion seen in EATL. CD30 expression is rarely seen in type II RCD, and is considered to be a sign of progression to EATL. ${ }^{8,178}$

\section{EIT L}

MEITL is a lymphoma derived from intraepithelial lymphocytes. It is unrelated to $\mathrm{CD}$, and is composed of medium-sized cells with round nuclei and pale cytoplasm, featuring epitheliotropism to the adjacent mucosa and lacking the inflammation and necrosis characteristic of EATL. MEITL occurs worldwide, but is the main form of primary intestinal T-cell lymphoma in Asia. ${ }^{163,179,180}$ The disease occurs in older adults, with a male predominance.

Patients may have non-specific symptomatology, such as abdominal pain and diarrhoea, or present with perforation, obstruction, abdominal masses, bleeding, or ascites. MEITL usually involves the jejunum, and less commonly the ileum or duodenum, sometimes with concurrent colonic lesion(s). Presentation in the colon or stomach is rare. Dissemination to regional lymph nodes and various distant organs may occur. The bone marrow is rarely involved $(5 \%){ }^{180-183}$ The prognosis is universally poor, despite aggressive treatment, and the median overall survival is $7-14.8$ months. ${ }^{179,180}$

\section{Pathological features}

MEITL (Figure 12) usually presents as an ulcerated, sometimes bulky, mass. The tumour comprises monotonous, small to medium-sized lymphoid cells with pale cytoplasm, dispersed chromatin, and inconspicuous nucleoli. Some cases show some pleomorphism but, unlike in EATL, there is no prominent inflammatory infiltrate, and necrosis is limited to the surface. The peritumoral mucosa shows prominent epitheliotropism and lesser involvement of the submucosa and muscularis propria. The distant mucosa may contain patchy foci with increased IEL without villous atrophy. ${ }^{179,181,183,184}$ Nevertheless, rare reports of cases with concomitant CD challenge the sporadic nature of the neoplasm. ${ }^{185}$

Immunohistochemically, the tumour cells are typically $\mathrm{CD} 2+, \quad \mathrm{CD} 3+, \quad \mathrm{CD} 7+, \quad \mathrm{CD} 4-, \quad$ and CD5-. ${ }^{163,176,179,181,183}$ Most cases are positive for CD8, CD56, and TIA1. Granzyme B is detected in two-thirds of the cases. Aberrant expression of CD20 or other B-cell antigens occurs in $20 \%$ of the cases, and CD 30 is mostly negative. Either TCR $\alpha \beta$ or TCR $\gamma \delta$ is usually expressed, whereas a small subset are TCRsilent. ${ }^{179-181,186,187}$ MATK expression has been reported as a characteristic marker in the majority of the cases. ${ }^{179,188}$ A recent study identified spleen tyrosine kinase (SYK) as a distinctive marker for MEITL (95\% versus $0 \%$ in EATL), pointing to a role of enhanced TCR signalling in MEITL. ${ }^{186}$ EBER expression may be seen in scattered B cells, but is consistently absent in the neoplastic $\mathrm{T}$ cells.

\section{Molecular and genetic features}

The majority of cases show monoclonal rearrangements of the TR genes. ${ }^{179,180,189}$ Genomic copy 


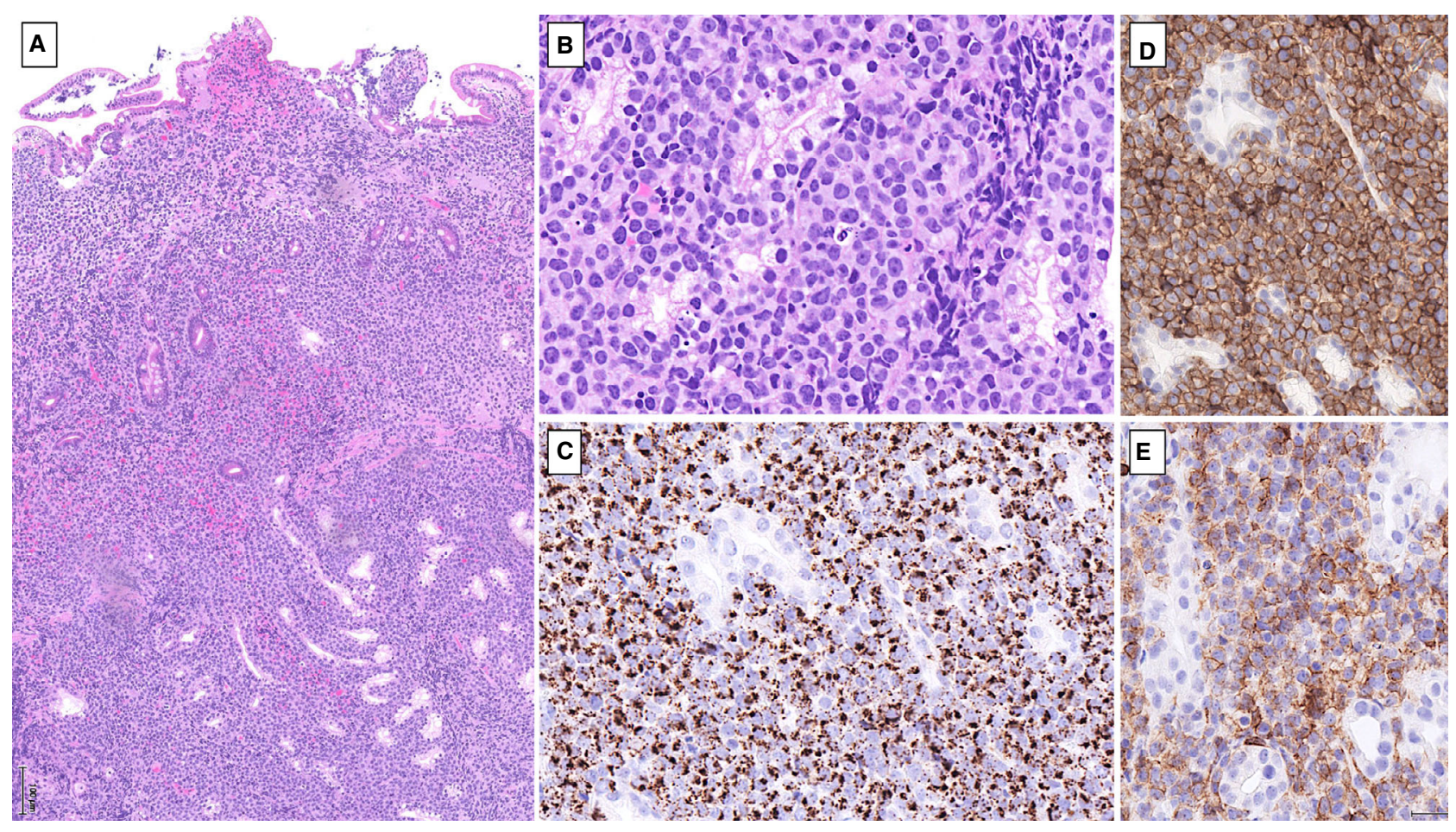

Figure 12. Monomorphic epitheliotropic intestinal T-cell lymphoma involving the duodenum. A, A dense lymphoma infiltrate obliterating the mucosa and submucosa [haematoxylin and eosin (H\&E)]. B, Medium-sized cells densely infiltrating the lamina propria and showing epitheliotropism to Brunner's glands (H\&E). C, Strong TIA1 expression. D, Diffuse positivity for CD56. E, Heterogeneous CD8 expression.

number alterations in common with EATL include gains of chromosomes $9 \mathrm{q}, 1 \mathrm{q}$, and $7 \mathrm{q} .{ }^{158,172,184}$ Alterations of chromosome 8 , i.e. loss or gain of $8 \mathrm{q}$, which includes $M Y C$, are significantly more frequent in MEITL than in EATL. ${ }^{172,179}$ A characteristic feature of MEITL consists of SETD2-disruptive mutations or deletions, which are present in $>90 \%$ of the cases. ${ }^{159}$ SETD2 encodes a lysine methyltransferase responsible for trimethylation of lysine 36 in histone H3. Immunohistochemically, SETD2-mutated cases have undetectable or reduced SETD2 expression, with concomitant low expression of histone $\mathrm{H} 3$ trimethylated on lysine $36 .{ }^{159}$ Mice with SETD2 loss showed expansion of $\gamma \delta \mathrm{T}$ cells, suggesting novel roles of the gene in T-cell development and an early event in lymphomagenesis. ${ }^{158}$ Inactivation of SETD2 has been demonstrated in many different tumour types, and seems to play a role in both disease initiation and disease progression. ${ }^{190}$ Other genes mutated in MEITLs and related to epigenetics include the histone acetyltransferase gene CREBBP (26\%) and EP3OO, EZH2, and ARID1, which are frequently mutated in B-cell lymphomas, whereas other genes that are frequently mutated in peripheral T-cell lymphomas (PTCLs), such as TET2, DNMT3A, and IDH1/2, are usually wild-type in MEITLs. ${ }^{159}$

Mutations activating the JAK-STAT pathway (especially in $S T A T 5 B, J A K 3$, and $S H 2 B 3$ ) are present in a large proportion of the cases. Mutually exclusive alterations affecting the MAPK pathway (BRAF, KRAS, NRAS, and TP53) are observed more frequently than in EATL, collectively in $\sim 80 \%$ of the cases. ${ }^{159,176}$ Mutations of GNAI2, which is a gene encoding a subunit of guanine nucleotide-binding protein, have been reported in $21 \%$ of MEITLs. ${ }^{191}$

Whole transcriptome sequencing analysis showed that genes overexpressed in MEITL as compared with EATL include FASLG, SYK, TGBR1, and NCAM1 (consistent with CD56 expression). ${ }^{158}$ Furthermore, enrichment for an NK-like cytotoxic signature, a known function of intraepithelial lymphocytes, was detected in MEITL. ${ }^{192}$

\section{Differential diagnosis}

The features of MEITL are usually sufficiently distinctive from those of EATL. Even if an increase in IEL may be seen in the mucosa distant from MEITL, villous atrophy is, in principle, absent. Expression of 
CD56 (and CD8) may suggest a diagnosis of ENKTCL (Figure 13), but MEITL is EBV-. In some cases, expression of B-cell markers may be confusing, and lead to consideration of a B-cell lymphoma.

\section{Indolent T/NK-cell entities}

I N D OLEN T T-CELL L Y M P H O P R OLIFER A T I VE DISORDER (ITLPD) OF THE GI TRACT

ITLPD of the GI tract is a new provisional entity defined as a clonal T-cell lymphoproliferation involving the GI mucosa, usually following a chronic and indolent course. ${ }^{7}$ ITLPD can occur at any age, but it usually occurs in middle-aged adults, with a slight male predominance (1.5:1). Symptoms include diarrhoea, vomiting, bloating, and abdominal pain. Some patients have been misdiagnosed as having RCD, and others have a history of inflammatory bowel disease, autoimmunity, or infection. ${ }^{161,193,194}$ Mucosal involvement is frequently multifocal, with a predilection for the small bowel and colon rather than the stomach. Mesenteric lymph nodes may be enlarged. Isolated cases of progression to other sites have been reported. ${ }^{161,193-197}$ Most patients are alive with persistent disease after several years of follow-up. Complete remission has been reported in two cases, ${ }^{161,198}$ and death from disease progression has been reported at 10-27 years after diagnosis in seven patients. ${ }^{194,196,199-201}$

\section{Pathological features}

Endoscopy may show nodules, mucosal polyps, fissures, and erosions. Some cases have no mucosal anomalies. Histologically, ITLPD features a non-destructive proliferation of small, monomorphic lymphocytes, which may infiltrate the muscularis mucosae or submucosa, and is associated with crypt hyperplasia. Mitoses and apoptoses are both inconspicuous; vascular invasion and necrosis are absent. Villous atrophy is infrequent, but IEL may be encountered. Scattered granulomas, lymphoid follicles or admixed eosinophils may be seen. Transformed cases comprise atypical cells and resemble PTCL.

Immunohistochemically, ITLPD is positive for CD3, CD2, and TCR $\beta F 1 .{ }^{161,194,201}$ Some cases show downregulation or loss of $\mathrm{CD} 5$ and/or CD7 expression. Most reported cases are $\mathrm{CD} 4+$, and less frequently $\mathrm{CD} 8+$, but double-negative (CD4- CD8-) or doublepositive $(\mathrm{CD} 4+\mathrm{CD} 8+)$ immunophenotypes have been described. They are negative for $\mathrm{T}$ follicular helpercell markers. A recent study investigating the cell of origin found that the $\mathrm{CD} 4+$ and double-positive cases
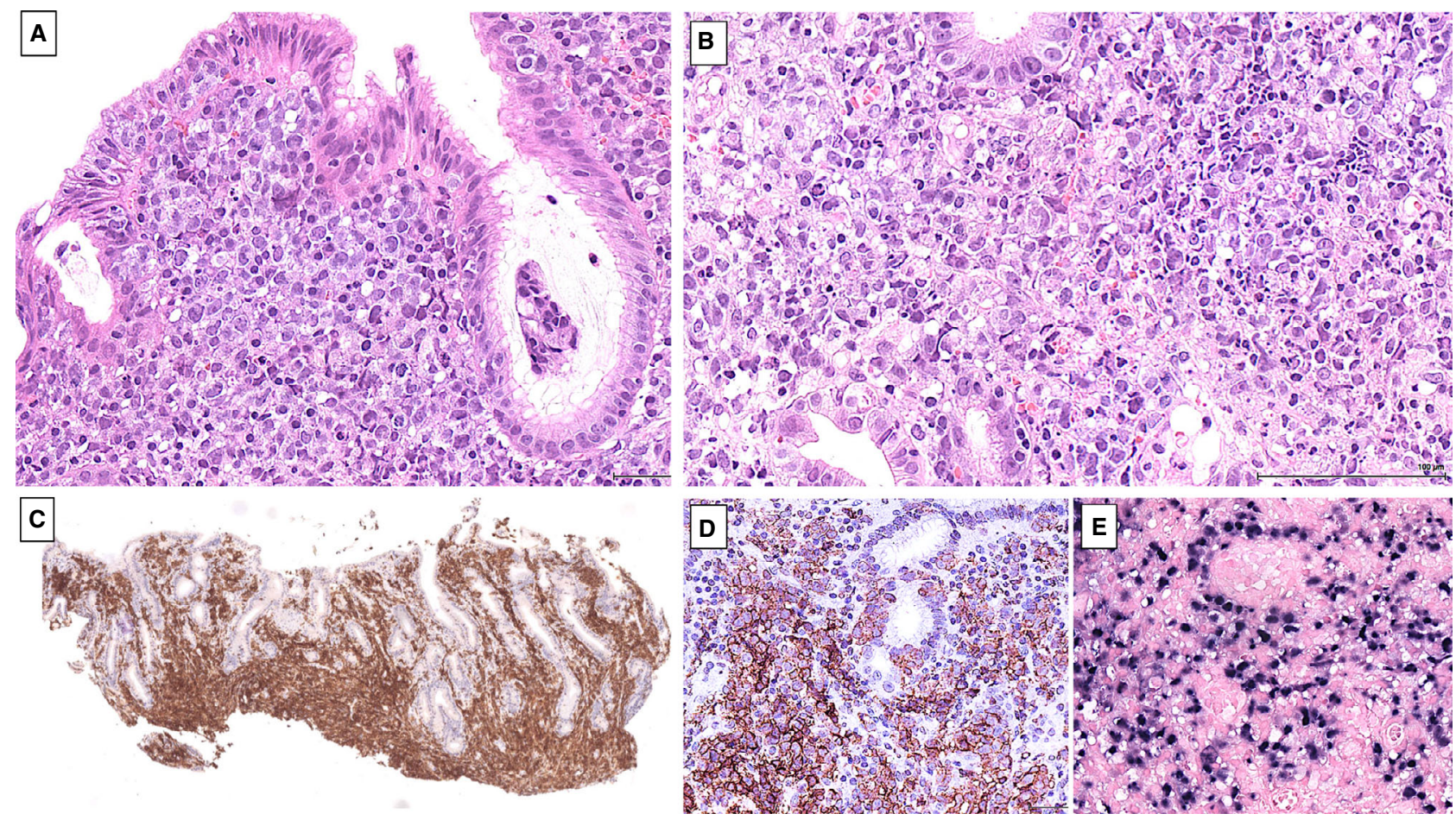

Figure 13. Extranodal natural killer/T-cell lymphoma, presenting in the stomach. A,B, Diffuse mucosal infiltrate comprising pleomorphic mediumsized to large cells (haematoxylin and eosin); note some epitheliotropism (A) and focal necrosis (B). C, Diffuse CD3 expression. D, Positivity for Tcell receptor- $\delta$. E, Positivity for Epstein-Barr virus by in-situ hybridisation. 
featured Th1 (T-bet+), Th2 (GATA3+) or hybrid Th1/ Th2 (T-bet+ GATA3+) profiles, whereas the majority of $\mathrm{CD} 8+$ cases and the double-negative cases showed a Th2-polarised (GATA3+) phenotype. ${ }^{194} \mathrm{CD} 8+$ cases express TIA1, but are negative for other cytotoxic markers. CD103 may be expressed, CD56 is usually negative, and there is no association with EBV. The Ki67 proliferation index is typically very low $(<5 \%)$. In one case, aberrant expression of CD20 was observed. Transformed cases may express MUM1/ IRF4, CD30, CD25, perforin, and granzyme B.

\section{Molecular genetics}

Genetic data on ITLPD are scarce, but indicate a burden of genetic aberrations lower than that in EATL/MEITL, and suggest a different pathogenesis for CD4+ and CD8+ cases. ${ }^{161,194,201}$ A study focused mostly on CD8+ ITLPD did not find phospho-STAT3 expression or STAT3 mutations. ${ }^{161}$ A STAT3-JAK2 fusion was reported in four of five cases of CD4+ ITLPD by Sharma et al., ${ }^{201}$ but a lower prevalence was found in subsequent studies, and the fusion has not been identified in $\mathrm{CD} 8+, \mathrm{CD} 4+\mathrm{CD} 8+$ or CD4 ${ }^{-} \mathrm{CD}^{-}$cases. $^{194}$ Cases harbouring the STAT3JAK2 fusion show phosphorylation of STAT5, and might be sensitive to JAK inhibitors. ${ }^{201,202}$ STAT3 mutations and SOCS1 deletion are other recurrent alterations found essentially in CD4+ cases. ${ }^{161,194}$ Other genetic aberrations include loss-of-function mutations in epigenetic modifier genes (TET2, DNMT3A, and KMT2D) and structural alterations of IL2 in CD8+ cases. $^{194}$

\section{Differential diagnosis}

ITLPD should be distinguished from inflammatory disorders, and from primary intestinal lymphomas. This distinction is particularly important, because the natural history is completely different, and ITLPDs do not either require or respond to chemotherapy. Clues to the correct diagnosis include the superficial nature of the lesions; the absence of mass formation and/or a destructive growth pattern; the bland cytology; and, the low proliferation index.

\section{NK-CELL ENTER OPATHY (NK CE)/LYMPHOM A T OID G A T T O P A TH Y}

NKCE was introduced in 2011 to designate indolent GI mucosal lymphoproliferations derived from NK cells, with a benign course and no clinicopathological

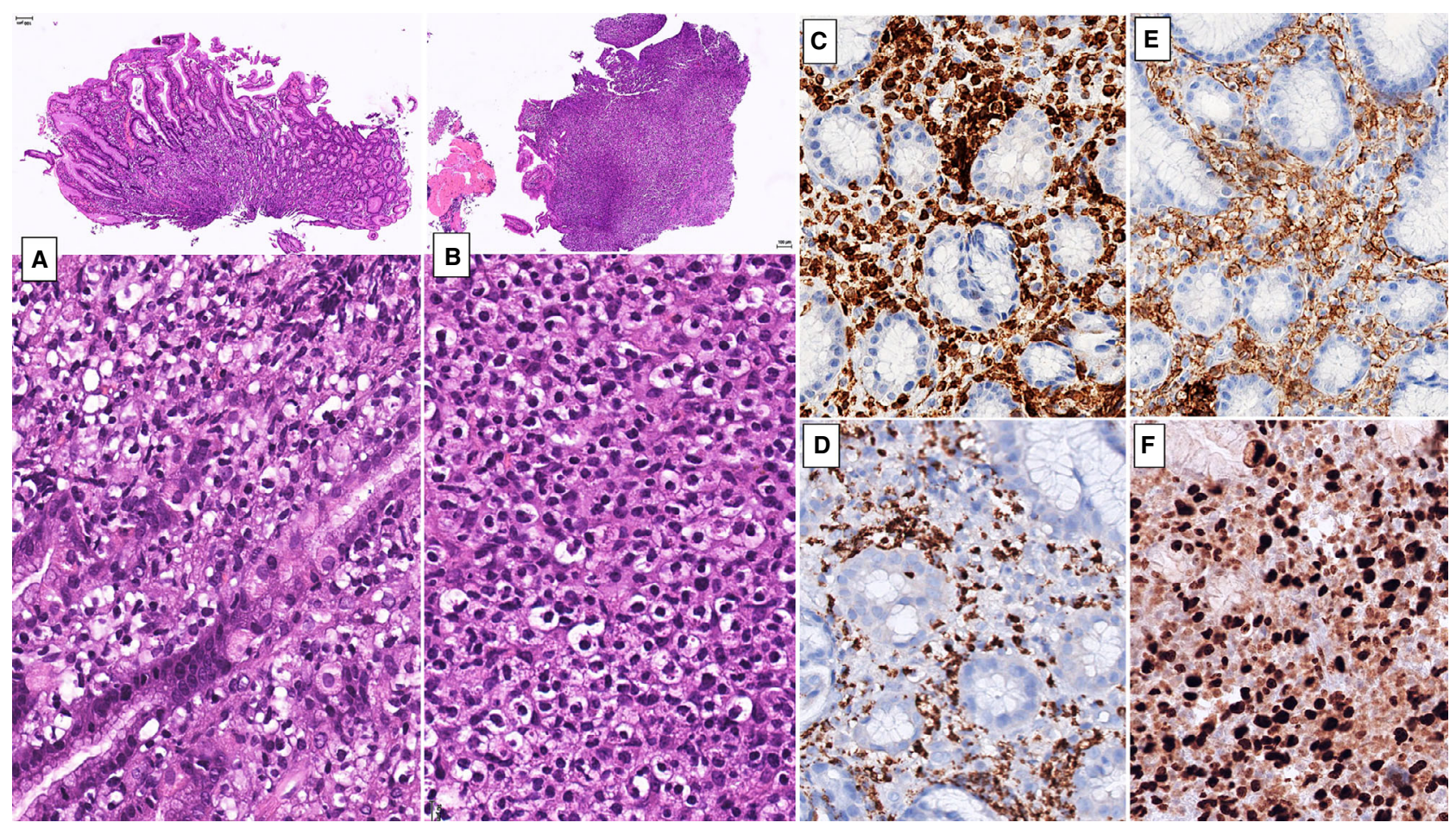

Figure 14. Natural killer-cell enteropathy involving the stomach (lymphomatoid gastropathy). A-D, Morphological features consisting of a mucosal infiltrate between the glands or partially destructive (C,D), composed of medium-sized cells with clear cytoplasm (B,D) (haematoxylin and eosin). E, CD3 immunopositivity. F, Perforin expression. G, CD56 expression. H, The Ki67 proliferation index was high in this case. Note that, on next-generation sequencing analysis, this case had a small in-frame hotspot deletion in JAK3. 
evidence to substantiate NK-cell lymphoma. ${ }^{203}$ The disorder was first described in the stomach, and has also been reported as 'lymphomatoid gastropathy'. ${ }^{204-206}$ NKCE is a rare disease, with <50 cases documented so far (reviewed in Dargent et al.; see references therein). ${ }^{178,203-209}$ Most cases occurred in middle-aged to older individuals, who were either asymptomatic or presented with mild and rather nonspecific GI symptoms. The majority of the cases occurred in the stomach, duodenum, or several upper GI sites, or involved both the upper and lower GI mucosa. Several gastric cases had concomitant $H$. pylori infection. The clinical course entails spontaneous resolution or persistence of the lesions for up to several years in some patients, despite various types of therapy. Unlike ITLPD of the GI tract, it has not yet been shown to progress to a more aggressive disease or cause nodal involvement.

At endoscopy, the altered mucosa often consists of erythematous, flat or polypoid lesions, superficial erosions, or ulcers. Histologically (Figure 14), NKCE features an atypical diffuse lymphoid infiltrate composed of medium-sized to large cells, with moderate clear or slightly eosinophilic cytoplasm, fine nuclear chromatin, and inconspicuous nucleoli. The infiltrate expands the lamina propria, with occasional epitheliotropism and glandular destruction, but lacks angiocentricity and necrosis. The atypical cells feature a $\mathrm{CD}^{+/}{ }^{+1} \mathrm{CD} 3+\mathrm{CD}^{-} \mathrm{CD}^{-} \mathrm{CD} 7+\mathrm{CD}^{-1+} \mathrm{CD} 56+\mathrm{NK}-$ cell immunophenotype, with an activated cytotoxic profile. The Ki67 proliferation index is variable, and is sometimes elevated. ${ }^{203,205-208}$ The cells in NKCE are $\mathrm{EBV}-$, which is a major feature distinguishing it from ENKTCL.

All cases lack clonal TR gene rearrangements, consistent with an NK-lineage derivation. In a recent study using a large haematology-oriented NGS panel, a somatic JAK3 mutation consisting of a small inframe deletion in exon 12 was identified in three of 10 NKCE cases. ${ }^{207}$ Other non-recurrent mutations involving PTPRS, AURKB, AXL, ERBB4, IGF1R, PIK3CB, CUL3, CHEK2, RUNX1T1, CIC, SMARCB1 and SETD5 were found in other cases. ${ }^{207}$ These findings support the neoplastic nature of the disorder, and may suggest potential therapeutic targets in some patients. ${ }^{207}$

\section{Conclusion}

A variety of lymphomas occur in the upper GI tract, and they are primarily diagnosed on endoscopic biopsies, which pose specific challenges, owing to limited sampling. The diagnosis of lymphoid infiltrates in these tissues primarily relies on careful morphological assessment complemented by immunophenotypic studies. Clonality assays, FISH studies and additional molecular genetic tests are complementary tools that are becoming increasingly useful or even mandatory to provide complete characterisation and accurate categorisation of the tumours. Importantly, endoscopic and clinical features are essential for providing a correct interpretation of the rare T-cell proliferations encountered in the stomach or small intestine.

\section{Conflicts of interest}

The authors have no conflicts of interest to disclose.

\section{Data sharing}

Data sharing is not applicable to this article, as no new data were created or analysed in this study.

\section{References}

1. Andrews CN, John Gill M, Urbanski SJ, Stewart D, Perini R, Beck P. Changing epidemiology and risk factors for gastrointestinal non-Hodgkin's lymphoma in a North American population: population-based study. Am. J. Gastroenterol. 2008; 103; $1762-1769$.

2. Howell JM, Auer-Grzesiak I, Zhang J, Andrews CN, Stewart D, Urbanski SJ. Increasing incidence rates, distribution and histological characteristics of primary gastrointestinal non-Hodgkin lymphoma in a North American population. Can. J. Gastroenterol. 2012; 26; 452-456.

3. Ding $W$, Zhao S, Wang J et al. Gastrointestinal lymphoma in Southwest China: subtype distribution of 1,010 cases using the WHO (2008) classification in a single institution. Acta Haematol. 2016; 135; 21-28.

4. Warrick J, Luo J, Robirds D et al. Gastrointestinal lymphomas in a North American population: clinicopathologic features from one major Central-Midwestern United States tertiary care medical center. Diagn. Pathol. 2012; 7; 76.

5. Koch P, del Valle F, Berdel WE et al. Primary gastrointestinal non-Hodgkin's lymphoma: I. Anatomic and histologic distribution, clinical features, and survival data of 371 patients registered in the German multicenter study GIT NHL 01/92. J. Clin. Oncol. 2001; 19; 3861-3873.

6. Nakamura S, Matsumoto T, Iida M, Yao T, Tsuneyoshi M. Primary gastrointestinal lymphoma in Japan: a clinicopathologic analysis of 455 patients with special reference to its time trends. Cancer 2003; 97; 2462-2473.

7. Swerdlow SH, Campo E, Harris N eds. World Health Organization classification of tumours of haematopoietic and lymphoid tissues. 4th ed. Lyon: IARC Press, 2017.

8. Lokuhetty D, White VA, Watanabe R eds. World Health Organization classification of tumours, digestive system tumours. 5th ed. Lyon: IARC Press, 2019.

9. Kohno S, Ohshima K, Yoneda S, Kodama T, Shirakusa T, Kikuchi M. Clinicopathological analysis of 143 primary malignant 
lymphomas in the small and large intestines based on the new WHO classification. Histopathology 2003; 43; 135-143.

10. Wang GB, Xu GL, Luo GY et al. Primary intestinal non-Hodgkin's lymphoma: a clinicopathologic analysis of 81 patients. World J. Gastroenterol. 2011; 17; 4625-4631.

11. Al-Saleem $\mathrm{T}, \mathrm{Al}$-Mondhiry $\mathrm{H}$. Immunoproliferative small intestinal disease (IPSID): a model for mature B-cell neoplasms. Blood 2005; 105; 2274-2280.

12. Bianchi G, Sohani AR. Heavy chain disease of the small bowel. Curr. Gastroenterol. Rep. 2018; 20; 3.

13. Ferreri AJ, Govi S, Ponzoni M. Marginal zone lymphomas and infectious agents. Semin. Cancer Biol. 2013; 23; 431-440.

14. Thieblemont C, Bertoni F, Copie-Bergman C, Ferreri AJ, Ponzoni M. Chronic inflammation and extra-nodal marginal-zone lymphomas of MALT-type. Semin. Cancer Biol. 2014; 24; 3342.

15. Doglioni C, Wotherspoon AC, Moschini A, de Boni M, Isaacson PG. High incidence of primary gastric lymphoma in northeastern Italy. Lancet 1992; 339; 834-835.

16. Parsonnet J, Hansen S, Rodriguez L et al. Helicobacter pylori infection and gastric lymphoma. N. Engl. J. Med. 1994; 330; $1267-1271$

17. Bertoni F, Zucca E. State-of-the-art therapeutics: marginalzone lymphoma. J. Clin. Oncol. 2005; 23; 6415-6420.

18. Raderer M, Osterreicher $\mathrm{C}$, Machold $\mathrm{K}$ et al. Impaired response of gastric MALT-lymphoma to Helicobacter pylori eradication in patients with autoimmune disease. Ann. Oncol. 2001; 12; 937-939.

19. Wotherspoon AC, Doglioni C, Diss TC et al. Regression of primary low-grade B-cell gastric lymphoma of mucosa-associated lymphoid tissue type after eradication of Helicobacter pylori. Lancet 1993; 342; 575-577.

20. Zullo A, Hassan C, Cristofari F et al. Effects of Helicobacter pylori eradication on early stage gastric mucosa-associated lymphoid tissue lymphoma. Clin. Gastroenterol. Hepatol. 2010; 8; $105-110$.

21. Nakamura S, Ye H, Bacon CM et al. Clinical impact of genetic aberrations in gastric MALT lymphoma: a comprehensive analysis using interphase fluorescence in situ hybridisation. Gut 2007; 56; 1358-1363.

22. Wotherspoon AC, Ortiz-Hidalgo C, Falzon MR, Isaacson PG. Helicobacter pylori-associated gastritis and primary B-cell gastric lymphoma. Lancet 1991; 338; 1175-1176.

23. Zucca E, Copie-Bergman C, Ricardi U et al. Gastric marginal zone lymphoma of MALT type: ESMO clinical practice guidelines for diagnosis, treatment and follow-up. Ann. Oncol. 2013; 24(Suppl. 6); vi144-vi148.

24. Sena Teixeira Mendes L, Attygalle AD, Wotherspoon AC. Helicobacter pylori infection in gastric extranodal marginal zone lymphoma of mucosa-associated lymphoid tissue (MALT) lymphoma: a re-evaluation. Gut 2014; 63; $1526-$ 1527.

25. Matysiak-Budnik T, Jamet P, Ruskone-Fourmestraux A et al. Gastric MALT lymphoma in a population-based study in France: clinical features, treatments and survival. Aliment. Pharmacol. Ther. 2019; 50; 654-663.

26. Isaacson PG, Du MQ. Gastrointestinal lymphoma: where morphology meets molecular biology. J. Pathol. 2005; 205; 255274.

27. Shinagare AB, Ramaiya NH, O'Regan K, Jagannathan JP, Hornick JL, LaCasce AS. Helicobacter pylori-negative gastric mucosa-associated lymphoid tissue lymphoma. J. Clin. Oncol. 2011; 29; e297-e300.
28. Ponzoni M, Ferreri AJ. Bacteria associated with marginal zone lymphomas. Best Pract. Res. Clin. Haematol. 2017; 30; $32-40$.

29. Mehra M, Agarwal B. Endoscopic diagnosis and staging of mucosa-associated lymphoid tissue lymphoma. Curr. Opin. Gastroenterol. 2008; 24; 623-626.

30. Zucca E, Arcaini L, Buske C et al. Marginal zone lymphomas: ESMO clinical practice guidelines for diagnosis, treatment and follow-up. Ann. Oncol. 2020; 31; 17-29.

31. Isaacson PG. Gastrointestinal lymphoma. Hum. Pathol. 1994; 25; $1020-1029$.

32. Isaacson PG. Update on MALT lymphomas. Best Pract. Res. Clin. Haematol. 2005; 18; 57-68.

33. Lai R, Weiss LM, Chang KL, Arber DA. Frequency of CD43 expression in non-Hodgkin lymphoma. A survey of 742 cases and further characterization of rare $\mathrm{CD} 43+$ follicular lymphomas. Am. J. Clin. Pathol. 1999; 111; 488-494.

34. Falini B, Tiacci E, Pucciarini A et al. Expression of the IRTA1 receptor identifies intraepithelial and subepithelial marginal zone $B$ cells of the mucosa-associated lymphoid tissue (MALT). Blood 2003; 102; 3684-3692.

35. Falini B, Agostinelli C, Bigerna B et al. IRTA1 is selectively expressed in nodal and extranodal marginal zone lymphomas. Histopathology 2012; 61; 930-941.

36. Wang Z, Cook JR. IRTA1 and MNDA expression in marginal zone lymphoma: utility in differential diagnosis and implications for classification. Am. J. Clin. Pathol. 2019; 151; 337343.

37. Hussell T, Isaacson PG, Crabtree JE, Spencer J. Helicobacter pylori-specific tumour-infiltrating $\mathrm{T}$ cells provide contact dependent help for the growth of malignant B cells in lowgrade gastric lymphoma of mucosa-associated lymphoid tissue. J. Pathol. 1996; 178; 122-127.

38. Mueller A, O'Rourke J, Chu P et al. The role of antigenic drive and tumor-infiltrating accessory cells in the pathogenesis of Helicobacter-induced mucosa-associated lymphoid tissue lymphoma. Am. J. Pathol. 2005; 167; 797-812.

39. Bende RJ, Aarts WM, Riedl RG, de Jong D, Pals ST, van Noesel CJ. Among B cell non-Hodgkin's lymphomas, MALT lymphomas express a unique antibody repertoire with frequent rheumatoid factor reactivity. J. Exp. Med. 2005; 201; 12291241.

40. Craig VJ, Arnold I, Gerke C et al. Gastric MALT lymphoma B cells express polyreactive, somatically mutated immunoglobulins. Blood 2010; 115; 581-591.

41. Du MQ, Xu CF, Diss TC et al. Intestinal dissemination of gastric mucosa-associated lymphoid tissue lymphoma. Blood 1996; 88; 4445-4451.

42. Sakuma H, Nakamura T, Uemura $\mathrm{N}$ et al. Immunoglobulin VH gene analysis in gastric MALT lymphomas. Mod. Pathol. 2007; 20; 460-466.

43. Xochelli A, Bikos V, Polychronidou E et al. Disease-biased and shared characteristics of the immunoglobulin gene repertoires in marginal zone B cell lymphoproliferations. J. Pathol. 2019; 247; 416-421.

44. Dierlamm J, Baens M, Wlodarska I et al. The apoptosis inhibitor gene API2 and a novel $18 \mathrm{q}$ gene, MLT, are recurrently rearranged in the $\mathrm{t}(11 ; 18)(\mathrm{q} 21 ; \mathrm{q} 21)$ associated with mucosaassociated lymphoid tissue lymphomas. Blood 1999; 93; 3601-3609.

45. Du MQ. MALT lymphoma: genetic abnormalities, immunological stimulation and molecular mechanism. Best Pract. Res. Clin. Haematol. 2017; 30; 13-23. 
46. Nakamura S, Ponzoni M. Marginal zone B-cell lymphoma: lessons from western and eastern diagnostic approaches. Pathology 2020; 52; 15-29.

47. Streubel B, Simonitsch-Klupp I, Mullauer L et al. Variable frequencies of MALT lymphoma-associated genetic aberrations in MALT lymphomas of different sites. Leukemia 2004; 18; $1722-1726$.

48. Ye $\mathrm{H}$, Liu $\mathrm{H}$, Attygalle A et al. Variable frequencies of $\mathrm{t}$ $(11 ; 18)(q 21 ; q 21)$ in MALT lymphomas of different sites: significant association with CagA strains of $H$ pylori in gastric MALT lymphoma. Blood 2003; 102; 1012-1018.

49. Remstein ED, Dogan A, Einerson RR et al. The incidence and anatomic site specificity of chromosomal translocations in primary extranodal marginal zone B-cell lymphoma of mucosaassociated lymphoid tissue (MALT lymphoma) in North America. Am. J. Surg. Pathol. 2006; 30; 1546-1553.

50. Streubel B, Vinatzer U, Lamprecht A, Raderer M, Chott A. T (3;14)(p14.1;q32) involving IGH and FOXP1 is a novel recurrent chromosomal aberration in MALT lymphoma. Leukemia 2005; 19; 652-658.

51. Levy M, Copie-Bergman C, Gameiro C et al. Prognostic value of translocation $\mathrm{t}(11 ; 18)$ in tumoral response of low-grade gastric lymphoma of mucosa-associated lymphoid tissue type to oral chemotherapy. J. Clin. Oncol. 2005; 23; 5061-5066.

52. Ye H, Liu H, Raderer M et al. High incidence of $\mathrm{t}(11 ; 18)(\mathrm{q} 21$; q21) in Helicobacter pylori-negative gastric MALT lymphoma. Blood 2003; 101; 2547-2550.

53. Starostik P, Patzner J, Greiner A et al. Gastric marginal zone B-cell lymphomas of MALT type develop along 2 distinct pathogenetic pathways. Blood 2002; 99; 3-9.

54. Liu H, Ye H, Ruskone-Fourmestraux A et al. $\mathrm{T}(11 ; 18)$ is a marker for all stage gastric MALT lymphomas that will not respond to H. pylori eradication. Gastroenterology 2002; 122; 1286-1294.

55. Ruskone-Fourmestraux A, Fischbach W, Aleman BM et al. EGILS consensus report. Gastric extranodal marginal zone Bcell lymphoma of MALT. Gut 2011; 60; 747-758.

56. Ye H, Gong L, Liu H et al. Strong BCL10 nuclear expression identifies gastric MALT lymphomas that do not respond to $H$ pylori eradication. Gut 2006; 55; 137-138.

57. Cascione L, Rinaldi A, Bruscaggin A et al. Novel insights into the genetics and epigenetics of MALT lymphoma unveiled by next generation sequencing analyses. Haematologica 2019; 104; e558-e561.

58. Kwee I, Rancoita PM, Rinaldi A et al. Genomic profiles of MALT lymphomas: variability across anatomical sites. Haematologica 2011; 96; 1064-1066.

59. Rinaldi A, Mian M, Chigrinova E et al. Genome-wide DNA profiling of marginal zone lymphomas identifies subtype-specific lesions with an impact on the clinical outcome. Blood 2011; 117; 1595-1604.

60. Schreuder MI, van den Brand M, Hebeda KM, Groenen P, van Krieken JH, Scheijen B. Novel developments in the pathogenesis and diagnosis of extranodal marginal zone lymphoma. J. Hematop. 2017; 10; 91-107.

61. Hyeon J, Lee B, Shin SH et al. Targeted deep sequencing of gastric marginal zone lymphoma identified alterations of TRAF3 and TNFAIP3 that were mutually exclusive for MALT1 rearrangement. Mod. Pathol. 2018; 31; 1418-1428.

62. Moody S, Escudero-Ibarz L, Wang M et al. Significant association between TNFAIP3 inactivation and biased immunoglobulin heavy chain variable region 4-34 usage in mucosa- associated lymphoid tissue lymphoma. J. Pathol. 2017; 243; 3-8.

63. Moody S, Thompson JS, Chuang SS et al. Novel GPR34 and CCR6 mutation and distinct genetic profiles in MALT lymphomas of different sites. Haematologica 2018; 103; 13291336.

64. Hummel M, Oeschger S, Barth TF et al. Wotherspoon criteria combined with B cell clonality analysis by advanced polymerase chain reaction technology discriminates covert gastric marginal zone lymphoma from chronic gastritis. Gut 2006; 55: 782-787.

65. Stasi R, Evangelista ML, Brunetti $\mathrm{M}$ et al. Primary gastric plasmacytoma and Helicobacter pylori infection. J. Clin. Oncol. 2009; 27; 150-153.

66. de Jong D, Boot H, van Heerde P, Hart GA, Taal BG. Histological grading in gastric lymphoma: pretreatment criteria and clinical relevance. Gastroenterology 1997; 112; 1466-1474.

67. Ferreri AJ, Freschi M, Dell'Oro S, Viale E, Villa E, Ponzoni M. Prognostic significance of the histopathologic recognition of low- and high-grade components in stage I-II B-cell gastric lymphomas. Am. J. Surg. Pathol. 2001; 25; 95-102.

68. Maeshima AM, Taniguchi H, Toyoda K et al. Clinicopathological features of histological transformation from extranodal marginal zone B-cell lymphoma of mucosa-associated lymphoid tissue to diffuse large B-cell lymphoma: an analysis of 467 patients. Br. J. Haematol. 2016; 174; 923-931.

69. Copie-Bergman C, Gaulard P, Lavergne-Slove A et al. Proposal for a new histological grading system for post-treatment evaluation of gastric MALT lymphoma. Gut 2003; 52; 1656.

70. Copie-Bergman C, Wotherspoon AC, Capella C et al. GELA histological scoring system for post-treatment biopsies of patients with gastric MALT lymphoma is feasible and reliable in routine practice. Br. J. Haematol. 2013; 160; 47-52.

71. Bacon CM, Du MQ, Dogan A. Mucosa-associated lymphoid tissue (MALT) lymphoma: a practical guide for pathologists. $J$. Clin. Pathol. 2007; 60; 361-372.

72. Fischbach W, Goebeler ME, Ruskone-Fourmestraux A et al. Most patients with minimal histological residuals of gastric MALT lymphoma after successful eradication of Helicobacter pylori can be managed safely by a watch and wait strategy: experience from a large international series. Gut 2007; 56; $1685-1687$.

73. Wundisch T, Stolte M. Current status of gastric MALT lymphoma. Curr. Gastroenterol. Rep. 2006; 8; 343-346.

74. Fischbach W, Goebeler-Kolve ME, Dragosics B, Greiner A, Stolte M. Long term outcome of patients with gastric marginal zone B cell lymphoma of mucosa associated lymphoid tissue (MALT) following exclusive Helicobacter pylori eradication therapy: experience from a large prospective series. Gut 2004; 53; 34-37.

75. Capelle LG, den Hoed CM, de Vries AC et al. Premalignant gastric lesions in patients with gastric mucosa-associated lymphoid tissue lymphoma and metachronous gastric adenocarcinoma: a case-control study. Eur. J. Gastroenterol. Hepatol. 2012; 24; 42-47.

76. Copie-Bergman C, Locher C, Levy M et al. Metachronous gastric MALT lymphoma and early gastric cancer: is residual lymphoma a risk factor for the development of gastric carcinoma? Ann. Oncol. 2005; 16; 1232-1236.

77. Palmela C, Fonseca C, Faria R, Baptista RB, Ribeiro S, Ferreira AO. Increased risk for metachronous gastric adenocarcinoma following gastric MALT lymphoma-a US population- 
based study. United European Gastroenterol. J. 2017; 5; 473478.

78. Rentien AL, Levy M, Copie-Bergman C et al. Long-term course of precancerous lesions arising in patients with gastric MALT lymphoma. Dig. Liver Dis. 2018; 50; 181-188.

79. Misdraji J, Harris NL, Hasserjian RP, Lauwers GY, Ferry JA. Primary follicular lymphoma of the gastrointestinal tract. Am. J. Surg. Pathol. 2011; 35; 1255-1263.

80. Yoshino T, Miyake K, Ichimura K et al. Increased incidence of follicular lymphoma in the duodenum. Am. J. Surg. Pathol. 2000; 24; 688-693.

81. Schmatz AI, Streubel B, Kretschmer-Chott E et al. Primary follicular lymphoma of the duodenum is a distinct mucosal/submucosal variant of follicular lymphoma: a retrospective study of 63 cases. J. Clin. Oncol. 2011; 29; 1445-1451.

82. Takata K, Okada H, Ohmiya N et al. Primary gastrointestinal follicular lymphoma involving the duodenal second portion is a distinct entity: a multicenter, retrospective analysis in Japan. Cancer Sci. 2011; 102; 1532-1536.

83. Takata K, Sato Y, Nakamura N et al. Duodenal follicular lymphoma lacks aid but expresses $\mathrm{BACH} 2$ and has memory B-cell characteristics. Mod. Pathol. 2013; 26; 22-31.

84. Tari A, Kitadai Y, Mouri R et al. Watch-and-wait policy versus rituximab-combined chemotherapy in Japanese patients with intestinal follicular lymphoma. J. Gastroenterol. Hepatol. 2018; 33; 1461-1468.

85. Kiess AP, Yahalom J. Primary follicular lymphoma of the gastrointestinal tract: effect of stage, symptoms and treatment choice on outcome. Leuk. Lymphoma 2013; 54; 177180.

86. Kitabatake H, Nagaya T, Tanaka N et al. Development of diffuse large B-cell lymphoma from follicular lymphoma of the duodenum: changes in endoscopic findings during a 6-year follow-up. Clin. J. Gastroenterol. 2017; 10; 79-85.

87. Miyata-Takata T, Takata K, Sato Y et al. A case of diffuse large B-cell lymphoma transformed from primary duodenal follicular lymphoma. Pathol. Int. 2014; 64; 527-532.

88. Sentani K, Maeshima AM, Nomoto J et al. Follicular lymphoma of the duodenum: a clinicopathologic analysis of 26 cases. Jpn. J. Clin. Oncol. 2008; 38; 547-552.

89. Bende RJ, Smit LA, Bossenbroek JG et al. Primary follicular lymphoma of the small intestine: $\alpha 4 \beta 7$ expression and immunoglobulin configuration suggest an origin from local antigen-experienced B cells. Am. J. Pathol. 2003; 162; 105113.

90. Huang WT, Hsu YH, Yang SF, Chuang SS. Primary gastrointestinal follicular lymphoma: a clinicopathologic study of 13 cases from Taiwan. J. Clin. Gastroenterol. 2008; 42; $997-$ 1002.

91. Papadakis KA, Prehn J, Nelson V et al. The role of thymus-expressed chemokine and its receptor CCR9 on lymphocytes in the regional specialization of the mucosal immune system. J. Immunol. 2000; 165; 5069-5076.

92. Wu W, Doan N, Said J, Karunasiri D, Pullarkat ST. Strong expression of chemokine receptor CCR9 in diffuse large B-cell lymphoma and follicular lymphoma strongly correlates with gastrointestinal involvement. Hum. Pathol. 2014; 45; 14511458.

93. Takata K, Sato Y, Nakamura N et al. Duodenal and nodal follicular lymphomas are distinct: the former lacks activation-induced cytidine deaminase and follicular dendritic cells despite ongoing somatic hypermutations. Mod. Pathol. 2009; 22; 940-949.
94. Hellmuth JC, Louissaint A Jr, Szczepanowski M et al. Duodenal-type and nodal follicular lymphomas differ by their immune microenvironment rather than their mutation profiles. Blood 2018; 132; 1695-1702.

95. Takata K, Tanino M, Ennishi D et al. Duodenal follicular lymphoma: comprehensive gene expression analysis with insights into pathogenesis. Cancer Sci. 2014; 105; 608-615.

96. Krysiak K, Gomez F, White BS et al. Recurrent somatic mutations affecting B-cell receptor signaling pathway genes in follicular lymphoma. Blood 2017; 129; 473-483.

97. Sato Y, Ichimura K, Tanaka T et al. Duodenal follicular lymphomas share common characteristics with mucosa-associated lymphoid tissue lymphomas. J. Clin. Pathol. 2008; 61; 377-381.

98. Ghimire P, Wu GY, Zhu L. Primary gastrointestinal lymphoma. World J. Gastroenterol. 2011; 17; 697-707.

99. Ruskone-Fourmestraux A, Delmer A, Lavergne A et al. Multiple lymphomatous polyposis of the gastrointestinal tract: prospective clinicopathologic study of 31 cases. Groupe d'etude des lymphomes digestifs. Gastroenterology 1997; 112; $7-16$.

100. Ruskone-Fourmestraux A, Audouin J. Primary gastrointestinal tract mantle cell lymphoma as multiple lymphomatous polyposis. Best Pract. Res. Clin. Gastroenterol. 2010; 24; 3542.

101. Michopoulos S, Petraki K, Matsouka C, Kastritis E, Chrysanthopoulou H, Dimopoulos MA. Mantle-cell lymphoma (multiple lymphomatous polyposis) of the entire GI tract. J. Clin. Oncol. 2008; 26; 1555-1557.

102. Romaguera JE, Medeiros LJ, Hagemeister FB et al. Frequency of gastrointestinal involvement and its clinical significance in mantle cell lymphoma. Cancer 2003; 97; 586-591.

103. Fraga M, Lloret E, Sanchez-Verde L et al. Mucosal mantle cell (centrocytic) lymphomas. Histopathology 1995; 26; 413-422.

104. Soldini D, Valera A, Sole C et al. Assessment of SOX11 expression in routine lymphoma tissue sections: characterization of new monoclonal antibodies for diagnosis of mantle cell lymphoma. Am. J. Surg. Pathol. 2014; 38; 86-93.

105. Martin-Garcia D, Navarro A, Valdes-Mas R et al. CCND2 and CCND3 hijack immunoglobulin light-chain enhancers in cyclin D1 ${ }^{-}$mantle cell lymphoma. Blood 2019; 133; 940951.

106. Salaverria I, Royo C, Carvajal-Cuenca A et al. CCND2 rearrangements are the most frequent genetic events in cyclin D1 ${ }^{-}$mantle cell lymphoma. Blood 2013; 121; 1394-1402.

107. Fichtner M, Dreyling M, Binder M, Trepel M. The role of B cell antigen receptors in mantle cell lymphoma. J. Hematol. Oncol. 2017; 10; 164.

108. Gemenetzi K, Agathangelidis A, Zaragoza-Infante L et al. B cell receptor immunogenetics in B cell lymphomas: immunoglobulin genes as key to ontogeny and clinical decision making. Front. Oncol. 2020; 10; 67.

109. Hill HA, Qi X, Jain P et al. Genetic mutations and features of mantle cell lymphoma: a systematic review and meta-analysis. Blood Adv. 2020; 4; 2927-2938.

110. Pararajalingam P, Coyle KM, Arthur SE et al. Coding and noncoding drivers of mantle cell lymphoma identified through exome and genome sequencing. Blood 2020; 136; $572-584$.

111. Zhao S, Kanagal-Shamanna R, Navsaria L et al. Efficacy of venetoclax in high risk relapsed mantle cell lymphoma (MCL) -outcomes and mutation profile from venetoclax resistant MCL patients. Am. J. Hematol. 2020; 95; 623-629. 
112. Jain P, Wang M. Mantle cell lymphoma: 2019 update on the diagnosis, pathogenesis, prognostication, and management. Am. J. Hematol. 2019; 94; 710-725.

113. Chuang SS, Diss T, Li CF. Primary gastric small lymphocytic lymphoma with perforation. Histopathology 2006; 49; 656658.

114. Menter T, Trivedi P, Ahmad R et al. Diagnostic utility of lymphoid enhancer binding factor 1 immunohistochemistry in small B-cell lymphomas. Am. J. Clin. Pathol. 2017; 147; 292-300.

115. Patel N, Durkin L, Bodo J, Hsi ED. Immunohistochemical expression of lymphoid enhancer binding factor 1 in CD5positive marginal zone, lymphoplasmacytic, and follicular lymphomas. Am. J. Clin. Pathol. 2020; 153; 646-655.

116. Rimsza L, Pittaluga S, Dirnhofer S et al. The clinicopathologic spectrum of mature aggressive B cell lymphomas. Virchows Arch. 2017; 471; 453-466.

117. Cheng Y, Xiao Y, Zhou R, Liao Y, Zhou J, Ma X. Prognostic significance of helicobacter pylori-infection in gastric diffuse large B-cell lymphoma. BMC Cancer 2019; 19; 842.

118. Ishikawa E, Nakamura M, Shimada K et al. Prognostic impact of PD-L1 expression in primary gastric and intestinal diffuse large B-cell lymphoma. J. Gastroenterol. 2020; 55; 39-50.

119. Ishikawa E, Tanaka T, Shimada K et al. A prognostic model, including the EBV status of tumor cells, for primary gastric diffuse large B-cell lymphoma in the rituximab era. Cancer Med. 2018; 7; 3510-3520.

120. Ferreri AJ, Govi S, Raderer M et al. Helicobacter pylori eradication as exclusive treatment for limited-stage gastric diffuse large B-cell lymphoma: results of a multicenter phase 2 trial. Blood 2012; 120; 3858-3860.

121. Kuo SH, Yeh KH, Wu MS et al. Helicobacter pylori eradication therapy is effective in the treatment of early-stage $H$ pyloripositive gastric diffuse large B-cell lymphomas. Blood 2012; 119; 4838-4844; quiz 5057.

122. Saito M, Masutani M, Mabe K et al. Regression of gastric de novo diffuse large B-cell lymphoma following Helicobacter pylori eradication: a case report. Acta Gastroenterol. Belg. 2016; 79; 367-369.

123. Hans CP, Weisenburger DD, Greiner TC et al. Confirmation of the molecular classification of diffuse large B-cell lymphoma by immunohistochemistry using a tissue microarray. Blood 2004; 103; 275-282.

124. Choi WW, Weisenburger DD, Greiner TC et al. A new immunostain algorithm classifies diffuse large B-cell lymphoma into molecular subtypes with high accuracy. Clin. Cancer Res. 2009; 15; 5494-5502.

125. Bobee V, Ruminy P, Marchand V et al. Determination of molecular subtypes of diffuse large B-cell lymphoma using a reverse transcriptase multiplex ligation-dependent probe amplification classifier: a CALYM study. J. Mol. Diagn. 2017; 19; 892-904.

126. Scott DW, Wright GW, Williams PM et al. Determining cellof-origin subtypes of diffuse large B-cell lymphoma using gene expression in formalin-fixed paraffin-embedded tissue. Blood 2014; 123; 1214-1217.

127. Chen YW, Hu XT, Liang AC et al. High BCL6 expression predicts better prognosis, independent of BCL6 translocation status, translocation partner, or BCL6-deregulating mutations, in gastric lymphoma. Blood 2006; 108; 2373-2383.

128. Zizhen Z, Hui C, Yanying S et al. Correlation between immunophenotype classification and clinicopathological features in Chinese patients with primary gastric diffuse large B-cell lymphoma. Pathol. Oncol. Res. 2013; 19; 317-322.

129. Connor J, Ashton-Key M. Gastric and intestinal diffuse large B-cell lymphomas are clinically and immunophenotypically different. An immunohistochemical and clinical study. Histopathology 2007; 51; 697-703.

130. Go JH, Yang WI, Ree HJ. CD10 expression in primary intestinal large B-cell lymphomas: its clinical significance. Arch. Pathol. Lab. Med. 2002; 126; 956-960.

131. Mitchell KA, Finn WG, Owens SR. Differences in germinal centre and non-germinal center phenotype in gastric and intestinal diffuse large B-cell lymphomas. Leuk. Lymphoma 2008; 49; 1717-1723.

132. Flossbach L, Antoneag E, Buck M et al. BCL6 gene rearrangement and protein expression are associated with large cell presentation of extranodal marginal zone B-cell lymphoma of mucosa-associated lymphoid tissue. Int. J. Cancer 2011; 129; 70-77.

133. Green TM, Nielsen O, de Stricker K, Xu-Monette ZY, Young $\mathrm{KH}$, Moller MB. High levels of nuclear MYC protein predict the presence of MYC rearrangement in diffuse large B-cell lymphoma. Am. J. Surg. Pathol. 2012; 36; 612-619.

134. Johnson NA, Slack GW, Savage KJ et al. Concurrent expression of MYC and BCL2 in diffuse large B-cell lymphoma treated with rituximab plus cyclophosphamide, doxorubicin, vincristine, and prednisone. J. Clin. Oncol. 2012; 30; 34523459.

135. Nakamura S, Ye H, Bacon CM et al. Translocations involving the immunoglobulin heavy chain gene locus predict better survival in gastric diffuse large B-cell lymphoma. Clin. Cancer Res. 2008; 14; 3002-3010.

136. Choi SY, Kim SJ, Kim WS, Kim K, Ko YH. Aggressive B cell lymphomas of the gastrointestinal tract: clinicopathologic and genetic analysis. Virchows Arch. 2011; 459; 495-502.

137. He M, Chen K, Li S et al. Clinical significance of 'double-hit' and 'double-protein' expression in primary gastric B-cell lymphomas. J. Cancer 2016; 7; 1215-1225.

138. van Krieken JH, Raffeld M, Raghoebier S, Jaffe ES, van Ommen GJ, Kluin PM. Molecular genetics of gastrointestinal non-Hodgkin's lymphomas: unusual prevalence and pattern of c-myc rearrangements in aggressive lymphomas. Blood 1990; 76; 797-800.

139. Yoshida N, Nomura K, Wakabayashi N et al. Cytogenetic and clinicopathological characterization by fluorescence in situ hybridization on paraffin-embedded tissue sections of twentysix cases with malignant lymphoma of small intestine. Scand. J. Gastroenterol. 2006; 41; 212-222.

140. Liang R, Chan WP, Kwong YL, Xu WS, Srivastava G, Ho FC. High incidence of BCL-6 gene rearrangement in diffuse large B-cell lymphoma of primary gastric origin. Cancer Genet. Cytogenet. 1997; 97; 114-118.

141. Chapuy B, Stewart C, Dunford AJ et al. Molecular subtypes of diffuse large B cell lymphoma are associated with distinct pathogenic mechanisms and outcomes. Nat. Med. 2018; 24; 679-690.

142. Schmitz R, Wright GW, Huang DW et al. Genetics and pathogenesis of diffuse large B-cell lymphoma. N. Engl. J. Med. 2018; 378; 1396-1407.

143. Dojcinov SD, Fend F, Quintanilla-Martinez L. EBV-positive lymphoproliferations of B- T- and NK-cell derivation in nonimmunocompromised hosts. Pathogens 2018; 7; 28.

144. Miyagi S, Ishikawa E, Nakamura M et al. Reappraisal of primary Epstein-Barr virus (EBV)-positive diffuse large B-cell 
lymphoma of the gastrointestinal tract: comparative analysis among immunosuppressed and nonimmunosuppressed stage I and II-IV patients. Am. J. Surg. Pathol. 2020; 44; 11731183.

145. Dojcinov SD, Venkataraman G, Raffeld M, Pittaluga S, Jaffe ES. EBV positive mucocutaneous ulcer-a study of 26 cases associated with various sources of immunosuppression. Am. J. Surg. Pathol. 2010; 34; 405-417.

146. Juan A, Lobaton T, Tapia G, Manosa M, Cabre E, Domenech E. Epstein-Barr virus-positive mucocutaneous ulcer in Crohn's disease. A condition to consider in immunosuppressed IBD patients. Dig. Liver Dis. 2017; 49; 934-937.

147. Roberts TK, Chen X, Liao JJ. Diagnostic and therapeutic challenges of EBV-positive mucocutaneous ulcer: a case report and systematic review of the literature. Exp. Hematol. Oncol. 2015; 5; 13.

148. Delecluse HJ, Anagnostopoulos I, Dallenbach F et al. Plasmablastic lymphomas of the oral cavity: a new entity associated with the human immunodeficiency virus infection. Blood 1997; 89; 1413-1420.

149. Liu Z, Filip I, Gomez K et al. Genomic characterization of HIV-associated plasmablastic lymphoma identifies pervasive mutations in the JAK-STAT pathway. Blood Cancer Discov. 2020; 1; 112-125.

150. Castillo JJ, Bibas M, Miranda RN. The biology and treatment of plasmablastic lymphoma. Blood 2015; 125; 2323-2330.

151. Sanguedolce F, Zanelli M, Zizzo M et al. Clinical, pathological and molecular features of plasmablastic lymphoma arising in the gastrointestinal tract: a review and reappraisal. Pathol. Res. Pract. 2020; 216; 152973.

152. Tavora F, Gonzalez-Cuyar LF, Sun CC, Burke A, Zhao XF, Extra-oral plasmablastic lymphoma: report of a case and review of literature. Hum. Pathol. 2006; 37; 1233-1236.

153. Valera A, Balague O, Colomo L et al. IG/MYC rearrangements are the main cytogenetic alteration in plasmablastic lymphomas. Am. J. Surg. Pathol. 2010; 34; 1686-1694.

154. Hsi ED, Lorsbach RB, Fend F, Dogan A. Plasmablastic lymphoma and related disorders. Am. J. Clin. Pathol. 2011; 136; 183-194.

155. Luria L, Nguyen J, Zhou J et al. Manifestations of gastrointestinal plasmablastic lymphoma: a case series with literature review. World J. Gastroenterol. 2014; 20; 11894-11903.

156. Taddesse-Heath L, Meloni-Ehrig A, Scheerle J, Kelly JC, Jaffe ES. Plasmablastic lymphoma with MYC translocation: evidence for a common pathway in the generation of plasmablastic features. Mod. Pathol. 2010; 23; 991-999.

157. Garcia-Reyero J, Magunacelaya NM, de Villambrosia SG et al. Genetic lesions in MYC and STAT3 drive oncogenic transcription factor overexpression in plasmablastic lymphoma. Haematologica 2020; 105. E-pub ahead of print, 9 April. https:// doi.org/10.3324/haematol.2020.251579

158. Moffitt AB, Ondrejka SL, McKinney M et al. Enteropathy-associated $\mathrm{T}$ cell lymphoma subtypes are characterized by loss of function of SETD2. J. Exp. Med. 2017; 214; 1371-1386.

159. Roberti A, Dobay MP, Bisig B et al. Type II enteropathy-associated T-cell lymphoma features a unique genomic profile with highly recurrent SETD2 alterations. Nat. Commun. 2016; 7; 12602 .

160. Matnani R, Ganapathi KA, Lewis SK, Green PH, Alobeid B, Bhagat G. Indolent T- and NK-cell lymphoproliferative disorders of the gastrointestinal tract: a review and update. Hematol. Oncol. 2017; 35; 3-16.
161. Perry AM, Warnke RA, Hu Q et al. Indolent T-cell lymphoproliferative disease of the gastrointestinal tract. Blood 2013; 122; 3599-3606.

162. Chander U, Leeman-Neill RJ, Bhagat G. Pathogenesis of enteropathy-associated $\mathrm{T}$ cell lymphoma. Curr. Hematol. Malig. Rep. 2018; 13; 308-317.

163. Delabie J, Holte H, Vose JM et al. Enteropathy-associated Tcell lymphoma: clinical and histological findings from the International Peripheral T-Cell Lymphoma Project. Blood 2011; 118; 148-155.

164. Soderquist CR, Bhagat G. Gastrointestinal T- and NK-cell lymphomas and indolent lymphoproliferative disorders. Semin. Diagn. Pathol. 2020; 37; 11-23.

165. van Vliet C, Spagnolo DV. T- and NK-cell lymphoproliferative disorders of the gastrointestinal tract: review and update. Pathology 2020; 52; 128-141.

166. Nijeboer P, de Baaij LR, Visser $O$ et al. Treatment response in enteropathy associated T-cell lymphoma; survival in a large multicenter cohort. Am. J. Hematol. 2015; 90; 493-498.

167. Bossard C, Dobay MP, Parrens M et al. Immunohistochemistry as a valuable tool to assess CD30 expression in peripheral T-cell lymphomas: high correlation with mRNA levels. Blood 2014; 124; 2983-2986.

168. Ashton-Key M, Diss TC, Pan L, Du MQ, Isaacson PG. Molecular analysis of T-cell clonality in ulcerative jejunitis and enteropathy-associated T-cell lymphoma. Am. J. Pathol. 1997; 151; 493-498.

169. Malamut G, Chandesris O, Verkarre V et al. Enteropathy associated $\mathrm{T}$ cell lymphoma in celiac disease: a large retrospective study. Dig. Liver Dis. 2013; 45; 377-384.

170. Murray A, Cuevas EC, Jones DB, Wright DH. Study of the immunohistochemistry and T cell clonality of enteropathy-associated T cell lymphoma. Am. J. Pathol. 1995; 146; 509519.

171. Cejkova P, Zettl A, Baumgartner AK et al. Amplification of NOTCH1 and ABL1 gene loci is a frequent aberration in enteropathy-type T-cell lymphoma. Virchows Arch. 2005; 446; 416-420.

172. Deleeuw RJ, Zettl A, Klinker E et al. Whole-genome analysis and HLA genotyping of enteropathy-type T-cell lymphoma reveals 2 distinct lymphoma subtypes. Gastroenterology 2007; 132: 1902-1911.

173. Obermann EC, Diss TC, Hamoudi RA et al. Loss of heterozygosity at chromosome $9 \mathrm{p} 21$ is a frequent finding in enteropathy-type T-cell lymphoma. J. Pathol. 2004; 202; 252-262.

174. Zettl A, deLeeuw R, Haralambieva E, Mueller-Hermelink HK. Enteropathy-type T-cell lymphoma. Am. J. Clin. Pathol. 2007; 127; 701-706.

175. Zettl A, Ott G, Makulik A et al. Chromosomal gains at 9q characterize enteropathy-type T-cell lymphoma. Am. J. Pathol. $2002 ; 161 ; 1635-1645$.

176. Nicolae A, Xi L, Pham TH et al. Mutations in the JAK/STAT and RAS signaling pathways are common in intestinal T-cell lymphomas. Leukemia 2016; 30; 2245-2247.

177. Nilsen EM, Jahnsen FL, Lundin KE et al. Gluten induces an intestinal cytokine response strongly dominated by interferon gamma in patients with celiac disease. Gastroenterology 1998; 115; 551-563.

178. Montes-Moreno S, King RL, Oschlies I et al. Update on lymphoproliferative disorders of the gastrointestinal tract: disease spectrum from indolent lymphoproliferations to aggressive lymphomas. Virchows Arch. 2020; 476; 667-681. 
179. Tan SY, Chuang SS, Tang T et al. Type II EATL (epitheliotropic intestinal T-cell lymphoma): a neoplasm of intra-epithelial T-cells with predominant $\mathrm{CD} 8 \alpha \alpha$ phenotype. Leukemia 2013; 27; 1688-1696.

180. Tse E, Gill H, Loong F et al. Type II enteropathy-associated Tcell lymphoma: a multicenter analysis from the Asia Lymphoma Study Group. Am. J. Hematol. 2012; 87; 663-668.

181. Chan JK, Chan AC, Cheuk W et al. Type II enteropathy-associated T-cell lymphoma: a distinct aggressive lymphoma with frequent $\gamma \delta$ T-cell receptor expression. Am. J. Surg. Pathol. 2011; 35; 1557-1569.

182. Chan TSY, Lee E, Khong PL, Tse EWC, Kwong YL. Positron emission tomography computed tomography features of monomorphic epitheliotropic intestinal T-cell lymphoma. Hematology 2018; 23; 10-16.

183. Kikuma K, Yamada K, Nakamura S et al. Detailed clinicopathological characteristics and possible lymphomagenesis of type II intestinal enteropathy-associated T-cell lymphoma in Japan. Hum. Pathol. 2014; 45; 1276-1284.

184. Tomita S, Kikuti YY, Carreras J et al. Genomic and immunohistochemical profiles of enteropathy-associated T-cell lymphoma in Japan. Mod. Pathol. 2015; 28; 1286-1296.

185. Lenti MV, Biagi F, Lucioni M, Di Sabatino A, Paulli M, Corazza GR. Two cases of monomorphic epitheliotropic intestinal T-cell lymphoma associated with coeliac disease. Scand. J. Gastroenterol. 2019; 54; 965-968.

186. Mutzbauer G, Maurus K, Buszello C et al. SYK expression in monomorphic epitheliotropic intestinal T-cell lymphoma. Mod. Pathol. 2018; 31; 505-516.

187. Sun J, Lu Z, Yang D, Chen J. Primary intestinal T-cell and NK-cell lymphomas: a clinicopathological and molecular study from China focused on type II enteropathy-associated T-cell lymphoma and primary intestinal NK-cell lymphoma. Mod. Pathol. 2011; 24; 983-992.

188. Tan SY, Ooi AS, Ang MK et al. Nuclear expression of MATK is a novel marker of type II enteropathy-associated T-cell lymphoma. Leukemia 2011; 25; 555-557.

189. Chuang SS, Chang ST, Chuang WY et al. NK-cell lineage predicts poor survival in primary intestinal NK-cell and T-cell lymphomas. Am. J. Surg. Pathol. 2009; 33; 1230-1240.

190. Chen R, Zhao WQ, Fang C, Yang X, Ji M. Histone methyltransferase SETD2: a potential tumor suppressor in solid cancers. J. Cancer 2020; 11; 3349-3356.

191. Nairismagi ML, Tan J, Lim JQ et al. JAK-STAT and G-proteincoupled receptor signaling pathways are frequently altered in epitheliotropic intestinal T-cell lymphoma. Leukemia 2016; 30; 1311-1319.

192. Meresse B, Curran SA, Ciszewski C et al. Reprogramming of CTLs into natural killer-like cells in celiac disease. J. Exp. Med. 2006; 203; 1343-1355.

193. Malamut G, Meresse B, Kaltenbach S et al. Small intestinal CD4+ T-cell lymphoma is a heterogenous entity with common pathology features. Clin. Gastroenterol. Hepatol. 2014; 12; 599-608.

194. Soderquist CR, Patel N, Murty VV et al. Genetic and phenotypic characterization of indolent T-cell lymphoproliferative disorders of the gastrointestinal tract. Haematologica 2020; 105; 1895-1906.

195. Leventaki V, Manning JT Jr, Luthra R et al. Indolent peripheral T-cell lymphoma involving the gastrointestinal tract. Hum. Pathol. 2014; 45; 421-426.

196. Margolskee E, Jobanputra V, Lewis SK, Alobeid B, Green PH, Bhagat G. Indolent small intestinal CD4+ T-cell lymphoma is a distinct entity with unique biologic and clinical features. PLoS One 2013; 8; e68343.

197. Svrcek M, Garderet L, Sebbagh V et al. Small intestinal CD4+ T-cell lymphoma: a rare distinctive clinicopathological entity associated with prolonged survival. Virchows Arch. 2007; 451; 1091-1093.

198. Isomoto $\mathrm{H}$, Maeda $\mathrm{T}$, Akashi $\mathrm{T}$ et al. Multiple lymphomatous polyposis of the colon originating from T-cells: a case report. Dig. Liver Dis. 2004; 36; 218-221.

199. Carbonnel F, d'Almagne H, Lavergne A et al. The clinicopathological features of extensive small intestinal CD4 T cell infiltration. Gut 1999; 45; 662-667.

200. Perry AM, Bailey NG, Bonnett M, Jaffe ES, Chan WC. Disease progression in a patient with indolent T-cell lymphoproliferative disease of the gastrointestinal tract. Int. J. Surg. Pathol. 2019; 27; 102-107.

201. Sharma A, Oishi N, Boddicker RL et al. Recurrent STAT3JAK2 fusions in indolent T-cell lymphoproliferative disorder of the gastrointestinal tract. Blood 2018; 131; 2262-2266.

202. Shouse G, Nikolaenko L. Targeting the JAK/STAT pathway in T cell lymphoproliferative disorders. Curr. Hematol. Malig. Rep. 2019; 14; 570-576.

203. Mansoor A, Pittaluga S, Beck PL, Wilson WH, Ferry JA, Jaffe ES. NK-cell enteropathy: a benign NK-cell lymphoproliferative disease mimicking intestinal lymphoma: clinicopathologic features and follow-up in a unique case series. Blood 2011; 117; 1447-1452.

204. Vega F, Chang CC, Schwartz MR et al. Atypical NK-cell proliferation of the gastrointestinal tract in a patient with antigliadin antibodies but not celiac disease. Am. J. Surg. Pathol. 2006; 30; 539-544.

205. Takata K, Noujima-Harada M, Miyata-Takata T et al. Clinicopathologic analysis of 6 lymphomatoid gastropathy cases: expanding the disease spectrum to CD4-CD8+ cases. Am. J. Surg. Pathol. 2015; 39; 1259-1266.

206. Takeuchi K, Yokoyama M, Ishizawa S et al. Lymphomatoid gastropathy: a distinct clinicopathologic entity of self-limited pseudomalignant NK-cell proliferation. Blood 2010; 116; 5631-5637.

207. Xiao W, Gupta GK, Yao J et al. Recurrent somatic jak3 mutations in NK-cell enteropathy. Blood 2019; 134; 986-991.

208. Xia D, Morgan EA, Berger D, Pinkus GS, Ferry JA, Zukerberg LR. NK-cell enteropathy and similar indolent lymphoproliferative disorders: a case series with literature review. Am. J. Clin. Pathol. 2019; 151; 75-85.

209. Dargent JL, Tinton N, Trimech M, de Leval L. Lymph node involvement by enteropathy-like indolent NK-cell proliferation. Virchows Arch. 2020. E-pub ahead of print, 21 July. https://doi.org/10.1007/s00428-020-02892-8 